\title{
DESIERTO, GANADO Y PICADAS PETROLERAS Construcción de una región de investigación para Añelo
}

Autor: Arq. Mijal Orihuela.

Becaria doctoral IPECHS-CONICET, docente investigador UFLO Sede Alto Valle, doctorando PPEU UNGS. Director CONICET: Dr. Joaquín Perren; Co-director CONICET: Dr. Arq. Guillermo Tella.

Email:mijal.orihuela@gmail.com

\section{RESUMEN}

La explotación de hidrocarburos no convencionales en las áreas Loma Campana y Loma La Lata - Sierra Barrosa, produjo, a partir del 2011, modificaciones en los actores interesados e intervinientes en las mismas. En este contexto, presumimos que la escasa incidencia demográfica y económica de las áreas afectadas han favorecido la invisibilización de dichos territorios y su población.

Por ello, proponemos aplicar la metodología de los Paisajes Culturales para describir este territorio. A tal fin, el objetivo de la presente ponencia consiste en construir una primera región de investigación, propuesta a partir de las características del ambiente físico (ecosistema, geomorfología, hidrografía, clima y recursos naturales) y sociodemográficas actuales.

En términos metodológicos, para cumplimentar el objetivo de este artículo, se realizará un relevamiento bibliográfico de la producción académica vinculada a dicho medio natural y de datos del Censo Nacional de Población, Hogares y Personas.

Palabras clave: Añelo - medio biofísico - paisaje - recursos naturales

\section{ABSTRACT}

The exploitation of unconventional hydrocarbons in the areas of Loma Campana and Loma La Lata - Sierra Barrosa, since 2011, has resulted in changes on the area's social matrix. In this context, we presume that the low demographic and economic incidence of the affected areas have favored the invisibility of said territories and their population.

Therefore, we propose to apply the methodology of Cultural Landscapes to describe this territory. To this end, the purpose of this paper is to build a first research region, proposed based on the characteristics of the physical environment (ecosystem, geomorphology, hydrography, climate and natural resources) and current sociodemographic.

In methodological terms, to complete the objective of this article, a bibliographic survey of the academic production linked to this natural environment and data from the National Population, Household and People Census will be made.

Key words: Añelo - biophysical environment - landscape - natural resources 


\section{1 .INTRODUCCIÓN}

La explotación de hidrocarburos no convencionales en la Formación Vaca Muerta, con epicentro en la localidad de Añelo, produjo, a partir del 2011, modificaciones en los actores interesados e intervinientes en el territorio bajo el cual se encuentra. Así mismo, induce a que la región sea objeto de múltiples presiones, evidenciadas en importantes movimientos migratorios, aumento de precios del suelo urbano y disputas por tierras aptas para la extracción de gas y petróleo. Si bien el impacto de la explotación de hidrocarburos no convencionales, de la cual se está realizando en la actualidad una "Prueba Piloto", se prevé en toda la zona noreste de la Provincia del Neuquén y norte de Rio Negro, el área petrolera de la Norpatagonia abarca las localidades de Plaza Huincul, Cutral Có, Catriel, Rincón de los Sauces, Neuquén, Allen y Añelo. Cada una de ellas con momentos de fundación y de auge extractivo diferentes, o, en otras palabras, procesos históricos de explotación y ocupación del territorio. Dichos procesos se traducen, a su vez, en dinámicas sociales particulares de cada ciudad, cuyo análisis superaría el alcance de nuestra investigación. Por ello tomamos una primera decisión de construir la región de estudio en torno a la localidad de Añelo, excluyendo las áreas de influencia de otras ciudades petroleras, ya que esta es la más cercana al área de "Prueba", donde se encuentran los yacimientos Loma Campana y Loma La Lata - Sierra Barrosa.

En este contexto, presumimos que la escasa incidencia demográfica y económica de la zona rural afectada por dichos yacimientos, ha favorecido la invisibilización de este territorio y su población. Se trata de una región poco poblada donde predomina la ganadería extensiva de supervivencia, los pozos petroleros y la vastedad de la estepa. En la Cuenca del rio Neuquén se suman a este paisaje los cultivos frutícolas y vitivinícolas, únicamente posibles luego importantes inversiones en sistematización de suelos y sistemas de riego artificial. Por ello, proponemos aplicar la metodología de los Paisajes Culturales (Sauer, 2006 [1925]; Pastor, 2008; Díaz Terreno, 2013) para describir este territorio de escala regional. Bajo el entendimiento de que la "región" es un fenómeno y producto que involucra a la sociedad y su espacio, resultado del correlato entre el sistema social y las formas de dominación vigentes (De Jong, 2001; Carbonari, 2009; Bandieri, 2014), el objetivo de la presente ponencia consiste en construir una primera región de investigación, propuesta a partir de las características del ambiente físico (ecosistema, geomorfología, hidrografía, clima y recursos naturales) y sociodemográficas actuales.
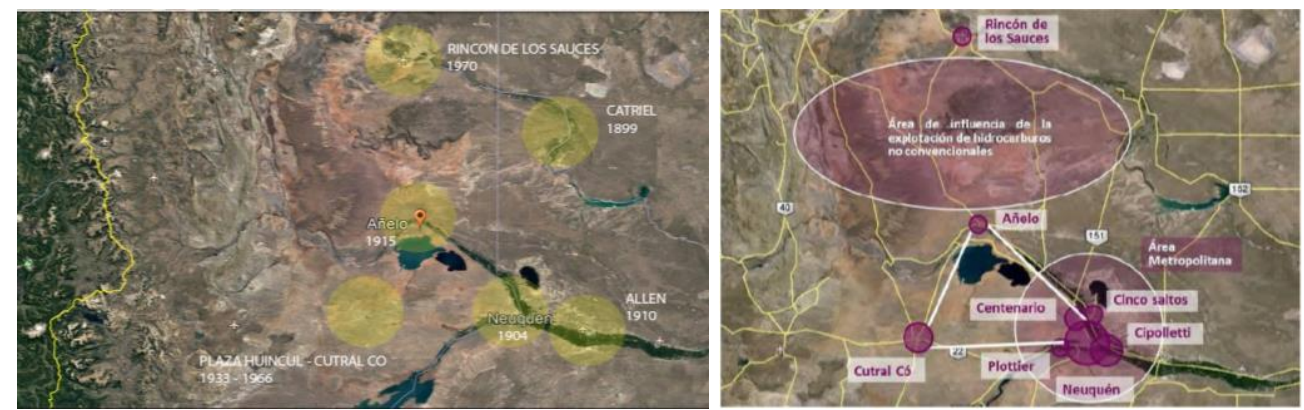

IZQUIERDA: Localización y año de fundación de las principales "ciudades petroleras" de la Norpatagonia Elaboración propia en base a imagen de Google Earth.

DERECHA: Ubicación de Añelo respecto de otras localidades de la provincia y área de influencia de la explotación de hidrocarburos no convencionales en la Formación Vaca Muerta

Fuente: Consultoría para la elaboración de proyectos ejecutivos para el mejoramiento urbano integral del centro de Añelo, Neuquén. Informe final, parte I.

El área de influencia de influencia prevista por YPF Idom se extiende entre la ciudad de Rincón de los Sauces al norte, la Ruta Nacional $N^{\circ} 40$ al oeste, la localidad de Añelo al sur y el rio Colorado al este a la altura de Catriel. Se trata de un área rural donde predomina la ganadería extensiva de supervivencia, que no incluye aglomeraciones urbanas importantes, aunque si varios parajes, entre los cuales cabe destacar el Aguada San Roque, Chihuido Norte, del Medio y Sur. Comprende, además, el Área Protegida Auca Mahuida, creada en 1996 por la Provincia del Neuquén, la cual se encuentra aislada de los circuitos y corredores turísticos de la región. Por último, cabe destacar que se extiende tanto sobre territorio neuquino como rionegrino. 
Sin embargo, las primeras etapas de explotación de hidrocarburos no convencionales, están previstas al sur de dicha zona de influencia, en las áreas hidrocarburíferas YPF Loma Campana y Loma La Lata - Sierra Barrosa, afectando las áreas inmediatas a las localidades de Añelo y el complejo hidroeléctrico Cerros Colorados.

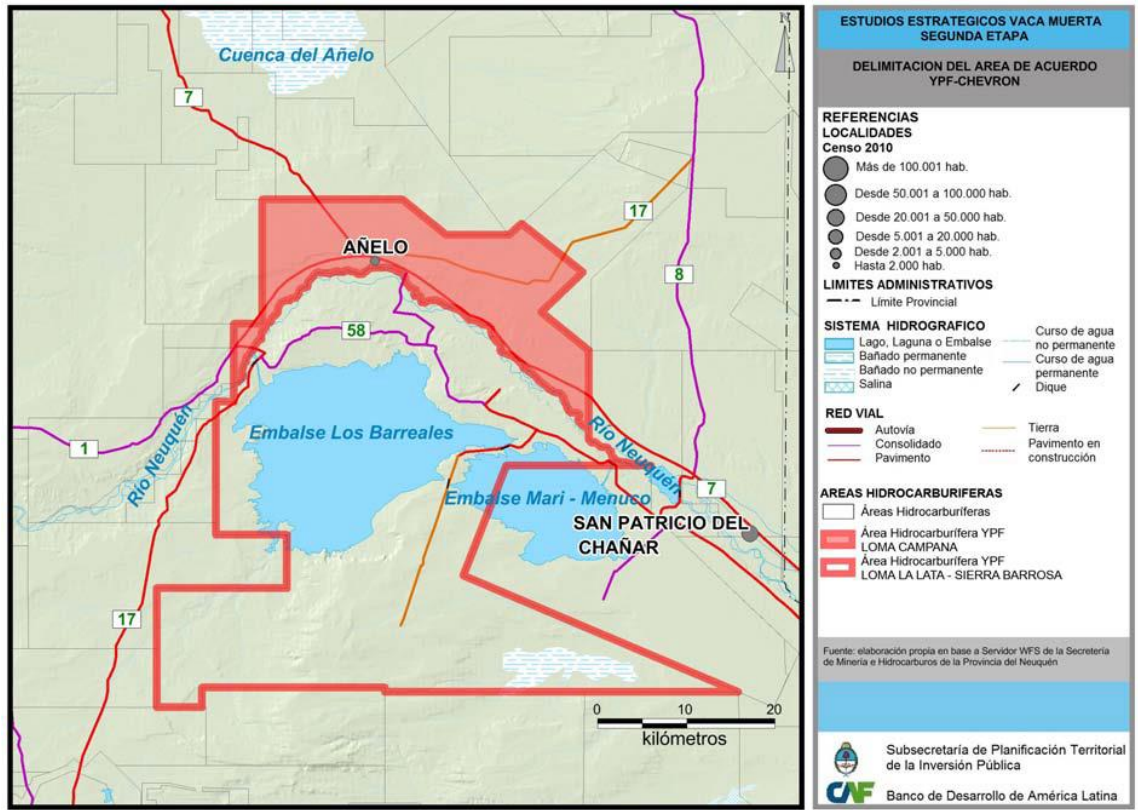

Área de pruebas piloto para la explotación de hidrocarburos no convencionales en la Formación Vaca Muerta Fuente: Estudios Estratégicos Vaca Muerta. Segunda Etapa

Estas cuestiones nos abren interrogantes respecto de cómo delimitar una región de estudio pertinente para Añelo, a fines de explicar cómo se ha construido su territorio como paisaje, pero considerando a la vez cómo se está reconstruyendo en la actualidad, en el marco de las nuevas exportaciones hidrocarburíferas. La construcción del territorio como paisaje es el resultado de la interacción entre el espacio geográfico y las estrategias de ocupación del mismo desarrolladas a lo largo del tiempo en él y sobre él, bajo la cual presumimos que subyacen modos particulares de organización territorial. En consecuencia, parece imprescindible, por un lado, conocer los procesos sociodemográficos y las causas que los impulsaron e impulsan, al igual que contar con un conocimiento detallado de la geografía en tanto condicionante a la vez de soporte que posibilita de las actividades humanas.

\section{UNA APROXIMACION SOCIODEMOGRAFICA}

Hasta el 2010, el máximo nivel de desagregación de los datos obtenidos en cada Censo Nacional de Población, Hogares y Viviendas es el nivel departamental, unidades jurisdiccionales que se mantienen estables en la Provincia del Neuquén desde 1915; por tanto, esta será la unidad elegida para el análisis sociodemográfico del territorio al cual nos estamos aproximando. Esta decisión nos obliga a preguntarnos ¿qué departamentos nos interesa considerar?

En primer lugar, nos interesa únicamente el territorio neuquino, dado que el norte rionegrino tiene mayor relación con la ciudad de Catriel que con la localidad de Añelo. En segundo lugar, el sector norte del departamento Confluencia, donde se localizan los embalses Los Barreales y Mari Menuco es un área escasamente poblada, que ha comenzado a utilizarse con fines turísticos en el presente milenio pero del cual los datos sociodemográficos 
a escala departamental no son representativos, ya que este departamento incluye la Ciudad de Neuquén y su área metropolitana, es decir, la zona más poblada de la provincia. En consecuencia, si bien nos interesa incorporar a nuestra región de estudio el Complejo Cerros Colorados y el área hidrocarburífera Loma La Lata - Sierra Barrosa, omitiremos los datos censales del departamento en el cual estos se encuentran.

En tercera instancia, los indicadores de los departamentos del noreste neuquino Pehuenches y Añelo, sobre los cuales se extiende el área de influencia de la extracción de hidrocarburos no convencionales, son históricamente similares, al punto de que algunos autores los analizan en forma conjunta (por caso: Fiori y Salva, 2000). Sin embargo, la localidad de Rincón de Los Sauces sufrió un crecimiento vertiginoso en las décadas de los noventa y dos mil (en el Censo 1991 contaba con 3.974 habitantes, en 2001 con 10.121 y en 2010 con 19.398), alterando la mencionada semejanza entre departamentos, al punto que en el último corte censal, la población total de Departamento de Añelo (10.786 habitantes) equivalía a poco más de la mitad de aquella. Por otra parte, el crecimiento de Rincón de Los Sauces conllevó una expansión de su área de influencia, la cual se extiende sobre el noreste neuquino. En consecuencia, optamos por analizar los datos sociodemográficos del Departamento de Añelo exclusivamente.
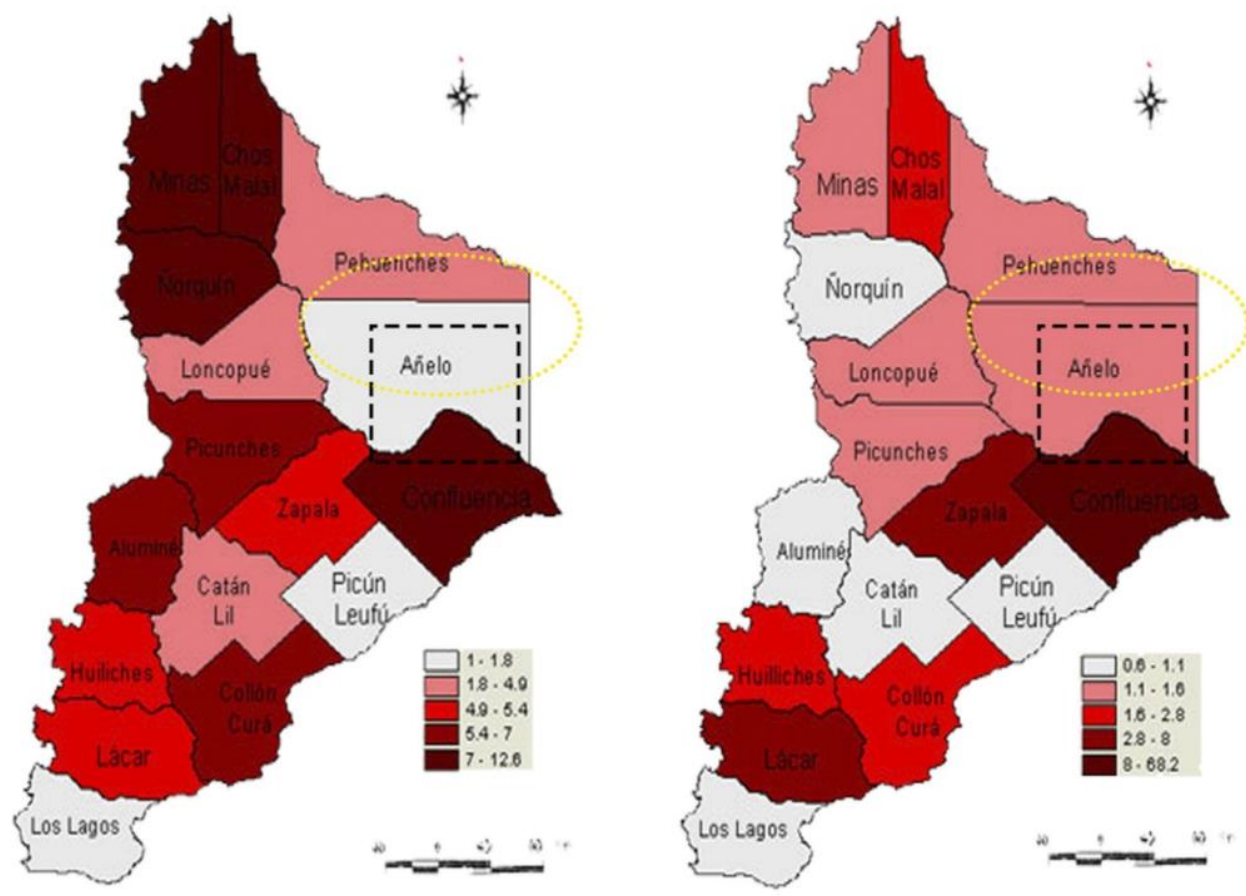

Distribución porcentual de la poblacion por departamentos, 1920 y 1991 Elaboración propia en base a Perren, 2008.

Como puede observarse en los mapas anteriores, el Departamento Añelo es históricamente uno de los más despoblados de la Provincia del Neuquén, si bien su población tiene a aumentar: en los periodos 1965 - 1970 , 1980 - 1991 y 1991 - 2010 su población se duplicó, sin embargo, su densidad es aun inferior a 1 hab/km². 


\begin{tabular}{|c|c|c|r|r|r|r|}
\hline Censo & $\begin{array}{c}\text { Superficie } \\
\text { en } \mathbf{K m}^{2}\end{array}$ & $\begin{array}{c}\text { Densidad } \\
\text { (hab/Km }\end{array}$ & \multicolumn{1}{l|}{$\begin{array}{l}\text { Población } \\
\text { Total }\end{array}$} & \multicolumn{1}{c|}{ Varones } & Mujeres & $\begin{array}{c}\text { Índice de } \\
\text { Masculinidad }\end{array}$ \\
\hline $\mathbf{1 9 2 0}$ & 11,655 & - & $\mathbf{3 2 6}$ & 164 & 162 & $\mathbf{1 0 1 . 2}$ \\
\hline $\mathbf{1 9 4 7}$ & 11,655 & $\mathbf{0 . 1}$ & $\mathbf{6 4 4}$ & 389 & 255 & $\mathbf{1 5 2 . 5}$ \\
\hline $\mathbf{1 9 6 0}$ & 11,655 & $\mathbf{0 . 1}$ & $\mathbf{7 7 8}$ & 457 & 321 & $\mathbf{1 4 2 . 4}$ \\
\hline $\mathbf{1 9 6 5}$ & 11,655 & $\mathbf{0 . 1}$ & $\mathbf{7 7 1}$ & 430 & 341 & $\mathbf{1 2 6 . 1}$ \\
\hline $\mathbf{1 9 7 0}$ & 11,655 & $\mathbf{0 . 1}$ & $\mathbf{8 0 0}$ & 461 & 339 & $\mathbf{1 3 6 . 0}$ \\
\hline $\mathbf{1 9 8 0}$ & 11,655 & $\mathbf{0 . 2}$ & $\mathbf{2 , 6 0 2}$ & 1,594 & 1,008 & $\mathbf{1 5 8 . 1}$ \\
\hline $\mathbf{1 9 9 1}$ & 11,655 & $\mathbf{0 . 4}$ & $\mathbf{4 , 6 6 8}$ & 2,583 & 2,085 & $\mathbf{1 2 3 . 9}$ \\
\hline $\mathbf{2 0 0 1}$ & 12,036 & $\mathbf{0 . 6}$ & $\mathbf{7 , 5 5 4}$ & 4,072 & 3,482 & $\mathbf{1 1 6 . 9}$ \\
\hline $\mathbf{2 0 1 0}$ & 11,655 & $\mathbf{0 . 9}$ & $\mathbf{1 0 , 7 8 6}$ & 5,677 & 5,109 & $\mathbf{1 1 1 . 1}$ \\
\hline
\end{tabular}

TABLA 1. Población total por sexo, razón de masculinidad (cantidad de varones cada 100 mujeres), superficie y densidad de población según censo, Departamento de Añelo, Provincia del Neuquén, periodo $1920-2010$.

Elaboración propia en base a datos del INDEC, Censo Nacional de Población, Hogares y Viviendas.

El índice de masculinidad refleja un aumento de la proporción de varones en la primera mitad del siglo XX, probablemente asociada a procesos migratorios, una tendencia al equilibrio en los años ' 60 y '70 y un nuevo aumento del sexo masculino para 1980, que está vinculada a la llegada de trabajadores hombres para la construcción del Embalse Cerros Colorados, la actividad petrolera y la frutihortícola. A partir de entonces, se observa una creciente tendencia hacia el equilibrio entre sexos.

La pirámide poblacional señala un nacimiento equilibrado de niñas y niños, así como una importante reducción en los niños entre 5 y 9 años respecto de los recién nacidos. Denota asimismo un leve incremento de los varones entre 10 y 19 años, así como entre 25 y 29 años; mientras que en el sexo femenino solo se observa un aumento en la adolescencia (15 a 19 años) pero este es mucho mayor que en el caso de los varones. En ambos sexos, pero en especial en el caso de las mujeres, se observa una reducción de la población entre los 20 y 24 años, lo cual podría estar señalando la migración de los jóvenes trabajadores hacia otras áreas de la provincia.

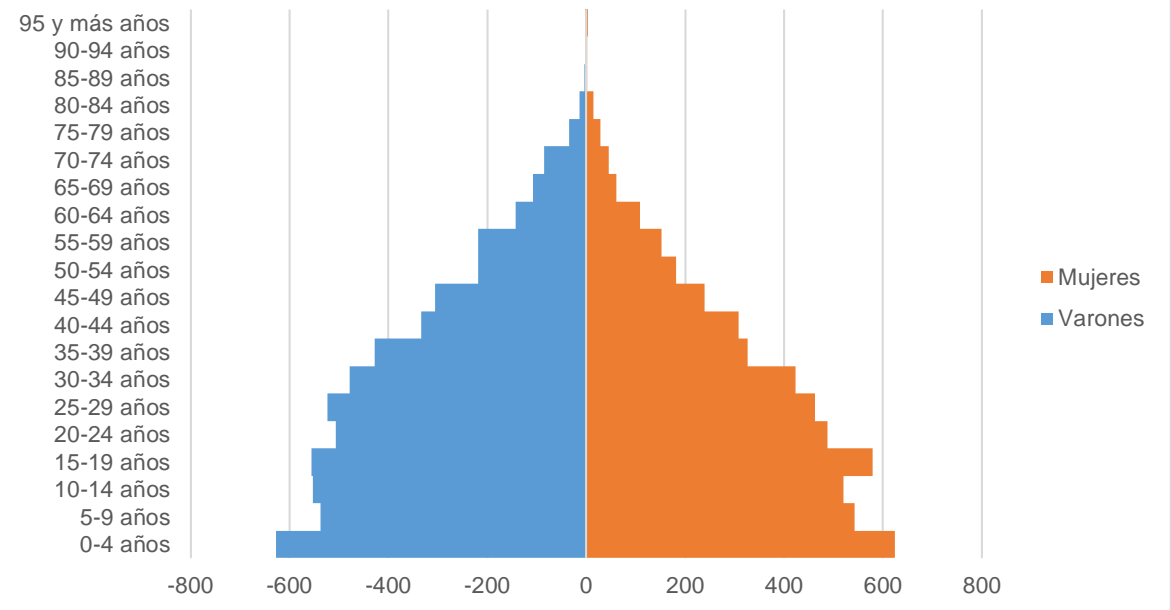

GRAFICO 1. Pirámide poblacional, Departamento de Añelo, Provincia del Neuquén, año 2010 Elaboración propia en base a datos del INDEC, Censo Nacional de Población, Hogares y Vivienda, 2010. 
El $20 \%$ de la población no alcanza a tener el primario completo, otro $60 \%$ no ha finalizado el secundario, el 12 $\%$ ha concluido dicho nivel y menos de un $4 \%$ cuenta con un título terciario o universitario. En los hogares sin necesidades básicas insatisfechas, un $60 \%$ de los pobladores sin secundario completo se encuentra ocupado, cifra que aumenta al $76 \%$ para quienes han alcanzado dicho nivel educativo; por otra parte, quienes no han finalizado estudios terciarios tienen empleo en el $64 \%$ de los casos y quienes lo han hecho, el porcentaje aumenta al $86 \%$. En el caso de los hogares con necesidades básicas insatisfechas (NBI), el $13 \%$ de los trabajadores con secundario completo se encuentre desocupado. Finalmente, cabe destacar que las personas sin primario completo en los hogares sin NBI representan el $18 \%$ de la población, pero el $27 \%$ en los hogares con NBI; los casos con primario completo o secundario completo constituyen el $60 \%$ en ambos tipos de hogares; secundario completo, el $13 \%$ de los hogares sin NBI y el $10 \%$ los hogares con NBl; mientras que terciario, completo incompleto, representa el 4-5\% en los hogares sin NBI y el 2-1\% en los hogares con NBI, es decir, que en los primeros duplica a los últimos.

\begin{tabular}{|c|c|c|c|c|c|c|c|c|c|c|c|c|c|c|c|c|c|c|c|c|c|}
\hline \multirow{4}{*}{$\begin{array}{l}\begin{array}{c}\text { Máximo Nivel de } \\
\text { Instrucción }\end{array} \\
\begin{array}{l}\text { Inicial o Primario } \\
\text { Incompleto }\end{array}\end{array}$} & \multirow{2}{*}{\multicolumn{8}{|c|}{$\begin{array}{c}\text { Hogares } \sin \text { NBI } \\
\text { Condición de actividad } \\
\end{array}$}} & \multirow{2}{*}{\multicolumn{8}{|c|}{$\begin{array}{c}\text { Hogares con NBI } \\
\text { Condición de actividad } \\
\end{array}$}} & \multirow{2}{*}{\multicolumn{5}{|c|}{$\begin{array}{c}\text { Total de hogares } \\
\text { Condición de actividad } \\
\end{array}$}} \\
\hline & & & & & & & & & & & & & & & & & & & & & \\
\hline & \multicolumn{2}{|c|}{ Ocupado } & \multicolumn{2}{|c|}{\begin{tabular}{|l|} 
Desocupado \\
\end{tabular}} & \multicolumn{2}{|c|}{ Inactivo } & \multicolumn{2}{|c|}{ Total } & \multicolumn{2}{|c|}{ Ocupado } & \multicolumn{2}{|c|}{\begin{tabular}{|l|} 
Desocupado \\
\end{tabular}} & \multicolumn{2}{|c|}{ Inactivo } & \multicolumn{2}{|c|}{ Total } & \multirow{2}{*}{\begin{tabular}{r|r} 
Ocupado & \\
886 &
\end{tabular}} & \multirow{2}{*}{\begin{tabular}{|r|} 
Desocupado \\
51
\end{tabular}} & \multirow{2}{*}{\begin{tabular}{r|} 
Inactivo \\
492 \\
\end{tabular}} & \multicolumn{2}{|c|}{ Total } \\
\hline & 620 & $60 \%$ & 39 & $4 \%$ & 377 & $36 \%$ & 1,036 & $18 \%$ & 266 & $68 \%$ & 12 & & 115 & & 393 & $27 \%$ & & & & 1,429 & $19.80 \%$ \\
\hline $\begin{array}{l}\text { Primario completo o } \\
\text { secundario incompleto }\end{array}$ & 2,062 & $60 \%$ & 157 & $5 \%$ & 1,228 & $36 \%$ & 3,447 & $60 \%$ & 507 & $57 \%$ & 41 & $5 \%$ & 349 & $39 \%$ & 897 & $61 \%$ & 2,569 & 198 & 1,577 & 4,344 & $60.18 \%$ \\
\hline Secundario completo & 568 & $76 \%$ & 34 & $5 \%$ & 143 & $19 \%$ & 745 & $13 \%$ & 89 & $62 \%$ & 18 & $13 \%$ & 36 & $25 \%$ & 143 & $10 \%$ & 657 & 52 & 179 & 888 & $12.30 \%$ \\
\hline $\begin{array}{l}\text { Superior no universitario } \\
\text { incompleto o universitario } \\
\text { incompleto }\end{array}$ & 159 & $64 \%$ & 15 & $6 \%$ & 76 & $30 \%$ & 250 & $4 \%$ & 15 & $65 \%$ & 1 & & 7 & $30 \%$ & 23 & $2 \%$ & 174 & 16 & 83 & 273 & $3.78 \%$ \\
\hline $\begin{array}{l}\text { Superior no universitario } \\
\text { o Universtiario completo }\end{array}$ & 230 & $86 \%$ & 8 & $3 \%$ & 29 & $11 \%$ & 267 & $5 \%$ & 16 & $94 \%$ & & & 1 & & 17 & $1 \%$ & 246 & 8 & 30 & 284 & $3.93 \%$ \\
\hline Total & 3,639 & $63 \%$ & 253 & $4 \%$ & 1,853 & $32 \%$ & 5,745 & $100 \%$ & 893 & $61 \%$ & 72 & $5 \%$ & 508 & $34 \%$ & 1,473 & $100 \%$ & 4,532 & 325 & 2,361 & 7.218 & $\mid 100.00 \%$ \\
\hline
\end{tabular}

TABLA 2. Condición de actividar

Provincia del Neuquén, 2010

Elaboración propia en base a datos del INDEC, Censo Nacional de Población, Hogares y Vivienda, 2010

Si se considera la calidad constructiva de la vivienda en relación con la locación y la cantidad de hogares que comprende, se observa que un $55 \%$ de las viviendas con un único hogar presentan una calidad satisfactoria, un $19 \%$ básica y un $25 \%$ insuficiente, porcentajes similares a los del total de viviendas. En las viviendas con más de un hogar, el $61 \%$ presenta una calidad satisfactoria, un $22 \%$ básica y un $17 \%$ insuficiente. Esto nos indica que la aglomeración de hogares en una única vivienda puede estar siendo utilizada como una estrategia hasta cierto punto efectiva para garantizarse una mejor calidad de vivienda o, por lo contrario, niveles de hacinamiento resultantes de la dificultad para acceder a la compra o alquiler de una vivienda. 


\begin{tabular}{|c|c|c|c|c|c|}
\hline \multirow{2}{*}{ Localidad } & \multirow{2}{*}{ Cantidad de Hogares en la Vivienda } & \multicolumn{3}{|c|}{ Calidad cons tructiva de la vivienda } & \multirow{2}{*}{ Total } \\
\hline & & Satisfactoria & Básica & Insuficiente & \\
\hline \multirow{3}{*}{$\begin{array}{c}\text { Zona rural } \\
\text { dispersa }\end{array}$} & Viviendas con un hogar & 166 & 131 & 296 & 593 \\
\hline & Viviendas con dos o más hogares & 4 & 2 & 1 & 7 \\
\hline & Total & 170 & 133 & 297 & 600 \\
\hline \multirow{2}{*}{$\begin{array}{c}\text { Aguada San } \\
\text { Roque }\end{array}$} & Viviendas con un hogar & 14 & 11 & 17 & 42 \\
\hline & Total & 14 & 11 & 17 & 42 \\
\hline \multirow{3}{*}{ Añelo } & Viviendas con un hogar & 461 & 141 & 128 & 730 \\
\hline & Viviendas con dos o más hogares & 8 & 7 & 1 & 16 \\
\hline & Total & 469 & 148 & 129 & 746 \\
\hline \multirow{3}{*}{$\begin{array}{r}\text { San Patricio } \\
\text { del Chañar }\end{array}$} & Viviendas con un hogar & 1,040 & 302 & 337 & 1,679 \\
\hline & Viviendas con dos o más hogares & 38 & 9 & 12 & 59 \\
\hline & Total & 1,078 & 311 & 349 & 1,738 \\
\hline \multirow{3}{*}{ TOTAL } & Viviendas con un hogar & 1,681 & 585 & 778 & 3,044 \\
\hline & Viviendas con dos o más hogares & 50 & 18 & 14 & 82 \\
\hline & Total & 1,731 & 603 & 792 & 3,126 \\
\hline
\end{tabular}

Tabla 5. Calidad constructiva de los hogares, según cantidad de hogares en la vivienda y locación, Departamento Añelo, Provincia del Neuquén, año 2010

Elaboración propia en base a datos del INDEC, Censo Nacional de Población, Hogares y Vivienda, 2010.

En otras palabras, se trata de un territorio que cuenta con una densidad poblacional baja a pesar de atraer población en forma sistemática, por lo cual su peso demográfico es aun insignificante. Su carácter es predominantemente rural: en 2010 su localidad más poblada era San Patricio del Chañar (fundada en 1973), con 7.457 habitantes, siguiéndole Añelo (1915) con 2.689 habitantes, los Paraje y Comisión de Fomento Sauzal Bonito (1989) y los Chihuidos (1915) con 274 habitantes cada uno, y el Paraje Aguada San Roque (fundado en 1915 y constituido como Comisión de Fomento en 1999), con 160 pobladores. Es, en síntesis, con escasos asentamientos poblaciones y ninguna aglomeración que alcance los 10.000 habitantes, una región despoblada donde un gran porcentaje de los habitantes se encuentran muy dispersos. Esta situación se ve perpetuada por un entramado conectivo pobre, que brinda escasas oportunidades de conexión a nivel intradepartamental y del Departamento con su entorno inmediato, con la excepción del Valle de Añelo, el cual se encuentra conectado con las ciudades de Neuquén, Plaza Huincul - Cutral Co y Rincon de Los Sauces por las rutas provinciales 7 y 17. La dispersión de los habitantes y la escasez de caminos de caminos consolidados ponen en evidencia el aislamiento de los pobladores del interior del Departamento. Por otra parte, si bien es una jurisdicción en la cual se extraen hidrocarburos y se produce fruta y vino para exportación, existen disparidades socioeconómicas entre sus habitantes, altos índices de necesidades básicas insatisfechas y grandes sectores de población que no accede a terminar sus estudios secundarios: el $20 \%$ de los hogares tiene necesidades básicas insatisfechas, el $45 \%$ de las viviendas no tiene una calidad constructiva satisfactoria y el $80 \%$ de la población en edad activa ha alcanzado como máximo el primario como nivel de instrucción formal. Estos indicadores, sumados a la dispersión poblacional y casi inexistencia de caminos consolidados en el territorio señalan escasez la de oportunidades para los habitantes del Departamento que lo ha convertido históricamente lo han hecho un área expulsiva; sin embargo, como puede inferirse del aumento poblacional de las últimas décadas, estas características se están revirtiendo gracias al desarrollo de áreas de producción frutihortícola intensiva bajo riego y de la actividad hidrocarburífera. 


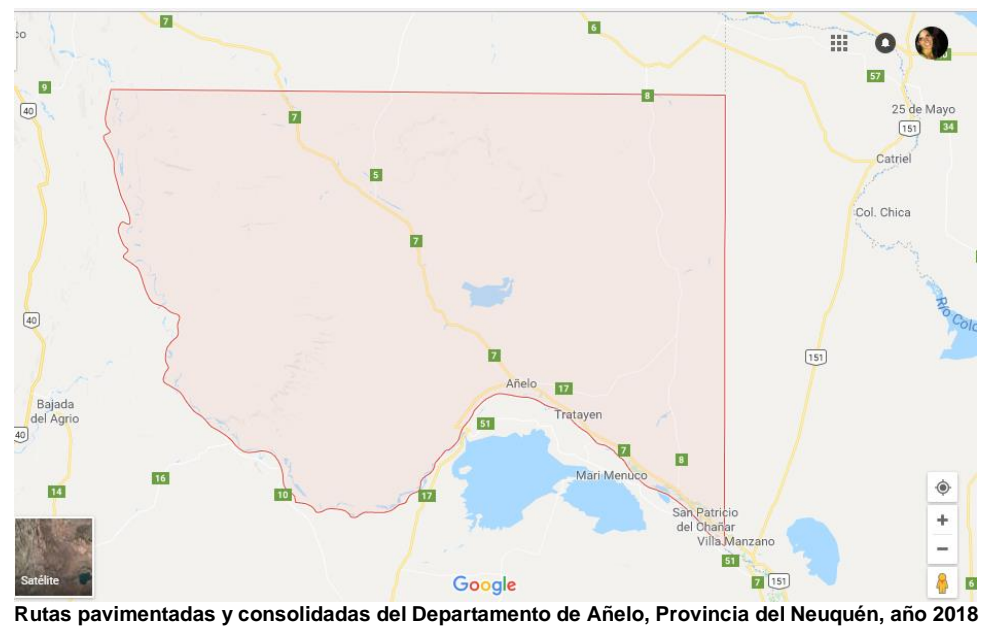

Rutas pavimentadas y consolidadas del Departamento de Añelo, Provincia del Neuquén, año 2018 Fuente: Google Maps https://www.google.com.ar/maps

\section{UN PAISAJE DESÉRTICO. CARACTERÍSTICAS GENERALES}

¿Cómo es el paisaje que resulta en un territorio relativamente poco poblado? ¿Es la dispersión de los habitantes resultado del carácter del paisaje regional? ¿Cuáles son sus límites? ¿Constituye el Departamento Añelo una unidad desde el punto de vista del clima, geomorfología, fisiografía y ecosistema? ¿Coinciden los límites departamentales con las unidades de paisaje naturales? En definitiva, ¿Cuál es la relación entre el espacio geográfico y las formas de ocupación del mismo?

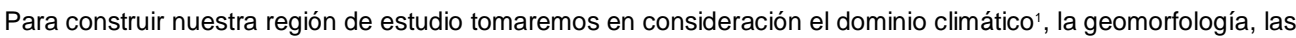
unidades fisiográficas y ecológicas.

\footnotetext{
${ }^{1}$ Un "dominio climático" es en geobotánica un área en la cual una asociación vegetal climatófila ejerce real o virtualmente la función de
} clímax, en la cual pueden, a su vez, reconocerse unidades de menor rango, que son más homogéneas. 

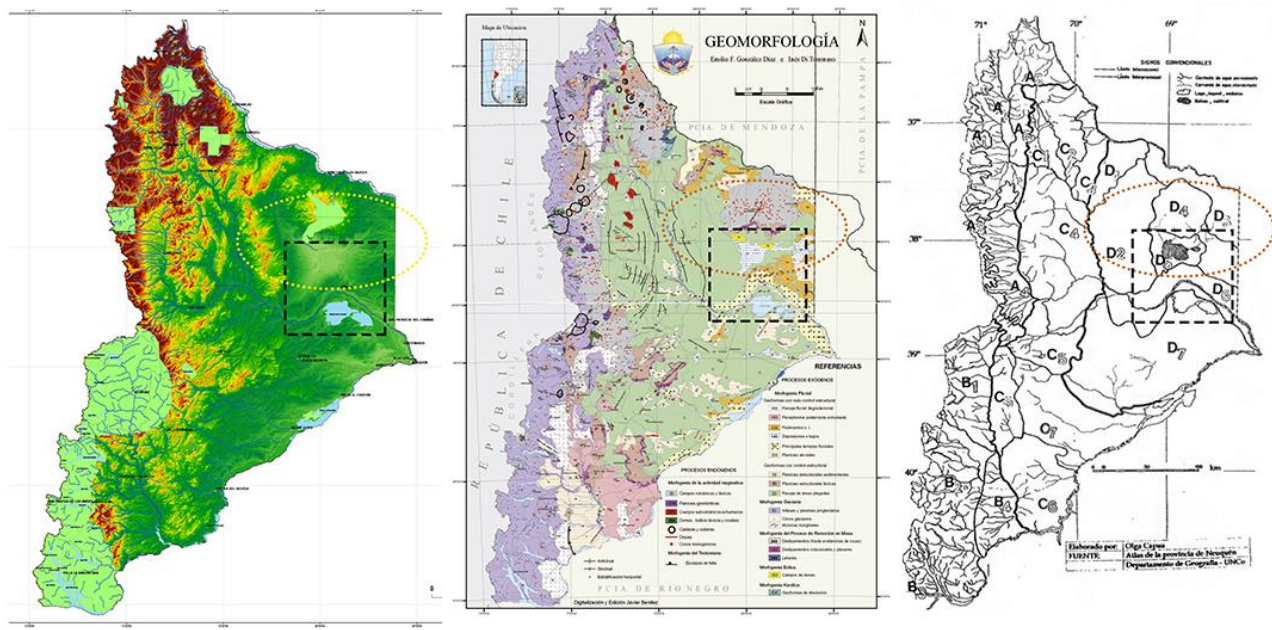

Mapa geoespacial (izquierda), Mapa geomorfológico (centro), Áreas fisiográficas y de paisaje (derecha) de la Provincia del Neuquén en relación al área de influencia de las explotaciones hidrocarburíferas no convencionales y al área de investigación (línea punteada negra)

Elaboración propia en base a mapa geoespacial del Instituto Nacional de Tecnologia Agropecuaria, González Díaz \& Di Tommasio (2011) y Capua (2003).

La región se localiza casi exclusivamente en el dominio climático semidesértico "diagonal árida", que recorre el país desde el noroeste hasta Tierra del Fuego y se caracteriza por contar con escasas precipitaciones y presentar rasgos orográficos similares. Se desarrolla además sobre un sector de la Cuenca Neuquina en la cual se encuentra la Formación Vaca Muerta, fuente de hidrocarburos no convencionales. Dicha Cuenca coincide con dos eco-regiones: la "Estepa Patagónica" y el "Monte de Llanuras y Mesetas". El sector de Estepa, localizado mayoritariamente en el Departamento Pehuenches, constituye un sector aislado que coincide con el sistema serrano Auca Mahuida e incluye la mayor parte del Area Protegida homónima, lo cual nos conduce a tomar una tercera decisión de establecer el límite norte de nuestra región de estudio al sur de dicho sistema serrano. Por otra parte, la mayor altitud que comienza a observarse con la aparición de Morenas Marginales en el Dorso de los Chihuidos a la altura de Paso de los Indios, nos incita a decidir en cuarto lugar tomar a este como límite oeste de nuestra región, quedando fuera de nuestra área de estudio los parajes Chihuido Sur, Norte y del Medio, cuyos procesos sociodemográficos se encuentran -a su vez- más asociados a la ciudad de Chos Malal y el norte neuquino que a la localidad de Añelo.

Según la clasificación de Capua (2003), el sector que nos interesa se desarrolla sobre la parte norte del "Área Oriental" de la Provincia del Neuquén. La autora divide dicha Área en siete sectores: Sierra Negra (D1), Dorso de los Chihuidos (D2), Llanuras aluviales vinculadas al antiguo curso del rio Colorado (D3), Auca Mahuida (D4), Cuenca de Añelo (D5), Depósitos aterrazados vinculados al curso inferior del rio Neuquén (D6), y, Deformaciones tabulares áridas (D7), sector que constituye el arquetipo del Área y es donde se localizan los embalses del Complejo Cerros Colorados. Si bien en términos sociodemográficos desestimamos el Departamento Confluencia, en el análisis biofísico no podemos obviar dicho complejo dada su cercanía física y funcional con el Valle de Añelo. Nos interesa, asimismo, el potencial agrícola de los Depósitos aterrazados vinculados al curso inferior del rio Neuquén, donde se encuentran el mencionado valle y, por tanto, la localidad de Añelo. También es necesario considerar la Cuenca de Añelo, en tanto es un área que presenta importantes limitantes no sólo al desarrollo agrícola, sino también de asentamientos poblacionales debido, principalmente, a la gran salinidad de los suelos. Por último, el Dorso de los Chihuidos, localizado tanto al este como al oeste de la Cuenca, nos interesa en sus aspectos generales pero no particulares, ya que, como dijimos anteriormente, nuestra área de estudio termina donde el Dorso comienza a ganar altitud. De este modo, Sierra Negra y las Llanuras aluviales vinculadas al antiguo curso del rio Colorado quedan totalmente excluidas de la región de estudio que estamos construyendo. 


\subsection{El "Monte de Llanuras y Mesetas": un ambiente desafiante}

La eco-región del "Monte de Llanuras y Mesetas" se extiende al este de la Cordillera de los Andes, desde el sur de San Juan hasta la costa atlántica de las provincias de Río Negro y Chubut, abarcando pequeños sectores de San Juan y San Luis, pero la mayor parte de Mendoza y Río Negro, así como importantes porciones de Neuquén, La Pampa y Chubut. Se caracteriza por paisajes relativamente planos debido a sus extensas mesetas escalonadas o llanuras, por su reducida peligrosidad sísmica y su gran aridez. Por otra parte, a pesar de su aparente horizontalidad, cuenta con diversidad tanto geológica como geomorfológica. Su relieve varía entre los 0 y 1000 m.s.n.m. e incluye cerros-mesa, cuerpos rocosos, depresiones, llanuras, valles intermontanos, cañadones y planicies de escasa pendiente que forman cuencas cerradas o semi-cerradas.

Las mesetas se desarrollan sobre sedimentos mesozoicos, que son poco resistentes a los procesos erosivos, y suelen estar coronadas por basalto o una capa de rodados cementados por carbonato de calcio (Capua, 2003). Luego, durante los periodos glaciales y peri-glaciales se depositó gran cantidad de rodado patagónico, sobre el cual, con el tiempo y por la acción de la erosión tanto eólica como fluvial, se asentó una capa de sedimentos arenosos y rocas de menor tamaño. En consecuencia, y en concordancia con el clima árido, los suelos son mayormente aridisoles o entisoles, es decir, arenosos, pobre en materia orgánica y, frecuentemente pedregosos; de textura gruesa, color claro y estructura débil por la mencionada escases de materia orgánica. Debido al déficit hídrico, cerca de la superficie pueden presentar acumulaciones salinas, calcáreas o yesosas. También por la aridez del clima, presentan falta de agua durante largos periodos. Cuando el agua se encuentra disponible la estructura y composición de los suelos no les permite retenerla, de modo que poseen grandes limitantes para la agricultura. Esta característica, sumada a la escasez de vegetación propia de los climas áridos, ha favorecido su asociación en el imaginario común con terrenos yermos y baldíos, sin embargo, la región alberga en su frágil ecosistema un importante número de especies vegetales y animales, algunas de ellas endémicas o casi exclusivas de la Patagonia y/o en riego de extinción.

En cuanto al clima, la amplitud térmica es pronunciada, con variaciones diarias mayores a $13^{\circ} \mathrm{C}$, aunque las temperaturas no son extremas, sino que las medias anuales son entre $10^{\circ} \mathrm{C}$ a $14^{\circ} \mathrm{C}$. La temperatura media en los meses invernales es de aproximadamente $7^{\circ} \mathrm{C}$, con mínimas de $-12^{\circ} \mathrm{C}$; en los meses estivales la media es de $20^{\circ} \mathrm{C}$ y la máxima de $43^{\circ} \mathrm{C}^{2}$. Por otra parte, como la horizontalidad del relieve, sumada a la escasa vegetación, no constituye obstáculos importantes para los vientos, estos son frecuentes y pueden superar los $100 \mathrm{~km} / \mathrm{h}$. Todos los meses del año hay vientos fuertes, que como mínimo rondan los $50 \mathrm{~km} / \mathrm{h}$, y que -a su vez- se registran aproximadamente cien días al año. En el periodo invernal provienen predominantemente del oeste y del sudoeste, mientras que en el estival se originan generalmente en el noreste. Los vientos más fuertes y frecuentes son por lo general los de octubre a febrero, en primavera y verano, y los más suaves los de abril y mayo, en otoño. Las diferencias son marcadas: mientras que en mayo son esperables cinco días de viento fuerte, en noviembre este número aumenta a catorce, asimismo, mientras en otoño los vientos fuertes rondan los $50 \mathrm{~km} / \mathrm{h}$, en febrero pueden alcanzar $70 \mathrm{~km} / \mathrm{h}$ a $100 \mathrm{~km} / \mathrm{h}$

Si bien los vientos del oeste son húmedos, ya que provienen del anticiclón del Pacifico Sur, el efecto Foëhn implica la pérdida de su humedad en la Cordillera de los Andes, a partir de la cual los vientos descienden rápidamente, aumentando la presión atmosférica y la temperatura, pero secos. Dado que la región también escapa la influencia húmeda tanto del océano Atlántico, la humedad ambiente media es de tan solo el $57 \%$ y las precipitaciones rondan los 100 a $200 \mathrm{~mm}$ anuales. El periodo más húmedo es el de otoño e invierno, cuando se generan bancos de niebla y neblina. Además, se producen heladas desde marzo hasta octubre, siendo las tardías de septiembre y octubre las más perjudiciales para la fruticultura, dado que pueden destruir las flores de los árboles, impidiendo que den frutos. En verano puede caer granizo, también perjudicial para la fruticultura dado que puede destruir los frutos en proceso de maduración. Si bien el déficit hídrico es una constante, la evotranspiración es aún mayor en el periodo estival, cuando la humedad es menor y las temperaturas elevadas. En lo que refiere a la producción frutihortícola, la inexistencia de excesos de agua en el suelo a lo largo de todo el año (Capua, 2003), las heladas tardías y el granizo, se traduce en su dependencia de sistemas de riego artificial.

\footnotetext{
${ }^{2}$ Estos datos corresponden a los generados por la Estación Meteorológica Cipolletti. En el área de estudio existen dos estaciones meteorológicas, la E. Cipolletti, perteneciente al Departamento de Aguas Rionegrinas, y la E. Neuquén AERO, del Servicio Meteorológico Nacional.
} 
En relación a la mencionada incapacidad de los suelos de retener el agua cuando esta se encuentra disponible, se torna especialmente agua en el periodo estival, debido a que, si bien llueve casi la misma cantidad de milímetros que en invierno, las precipitaciones de verano son más esporádicas, breves y, por tanto, torrenciales. Esto se debe a que son de origen mayormente convectivo (Capua, 2003), es decir, resultado a movimientos de aire verticales, producidos por el ingreso de aire húmedo y el recalentamiento del suelo. Ello provoca que el impacto de las primeras gotas en un suelo reseco y recalentado, produzca la dispersión de sus agregados, que se mantienen en suspensión hasta que comienzan a acompañar el agua que se infiltra hasta obturar los poros del suelo y formar una costra resistente a la infiltración que produce el escurrimiento superficial del agua. Cuando dicha escorrentía es muy rápida y uniforme, el agua discurre por la ladera sin llegar a originar incisiones, pero si no se concentra en forma lineal, formando canales poco profundos ("rills") que pueden convertirse en el "carcavamiento" (Capua, 2003) típico de la meseta.

El déficit hídrico incrementa la importancia del sistema hidrográfico, caracterizado por un índice hídrico estival marcado, con cursos de agua temporarios y zonas de extinción de numerosas cuencas. Añelo se localiza sobre la cuenca del rio Neuquén, uno de los afluentes del Rio Negro, que es uno de los cursos de agua más importantes de la eco-región. Al igual que los otros ríos del Monte, el rio Neuquén corre en dirección oeste - este y es un rio caudaloso con crecientes devastadoras, que fueron controladas mediante la ejecución del Dique Ballesteros y el canal derivador Arroyón, posibilitando el desvío de las aguas al Lago Pellegrini o Cuenca Vidal durante las crecidas extraordinarias. Una vez controladas las crecidas, fue posible construir sistemas de riego con los que irrigar el valle fluvial.

En la década de 1960, la búsqueda de un aprovechamiento integral del sistema hídrico impulsó, además, la construcción del complejo hidroeléctrico Cerros Colorados en Planicie Banderita. El complejo, construido en el periodo 1969 -1980, aprovecha dos depresiones naturales para generar los lagos artificiales Los Barreales y Mari Menuco, y cuenta con una potencia instalada de $479 \mathrm{MW}$, con las que genera una media de $1.512 \mathrm{GWh}$. Constituye parte de un conjunto de complejos que incluyen El Chocón (1969 - 1977), Alicurá (1985), Piedra del Águila (1985 - 1993) en el rio Limay y Casa de Piedra (1983 - 1996) en el rio Colorado, así como los proyectos para la construcción Chihuido I y II, también en el rio Neuquén. Este tipo de obras brindan una alternativa al uso de energía fósil, sin embargo, no generan una energía totalmente "limpia", ya que provocan serios cambios en las condiciones ambientales y para la flora y fauna.

\subsection{Flora, fauna y desertificación}

A pesar de la aridez, el ecosistema presenta una rica flora y fauna, que incluye especies endémicas y raras. En relación con la flora, en los valles fluviales, es decir, las zonas cercanas a los cursos de agua poseen suelos fértiles, debido al sedimento aluvional que las crecidas naturales de los ríos depositaban periódicamente sobre ellos, lo que permite el desarrollo de agricultura intensiva bajo riego en estas áreas. Además, en los sitios donde los cursos y espejos de agua mantienen húmedo el suelo la vegetación incluye arbustos que pueden alcanzar los $3 \mathrm{~m}$ de alto y árboles como el sauce criollo (Salix humboldtiana) que puede formar bosquecillos (Bonino, 2005), el carrizo (Phragmites australis), vidriera (Suaeda divaricata), pichana (Senna aphylla), pelo de chancho (Distichlis sp) y pata de loro (Prosopis strombulifera).

En la meseta, por otra parte, donde predominan las características detalladas más arriba, los ambientes son xerófitos, brindando "un panorama fisonómicamente homogéneo del tipo estepa arbustiva" (Capua, 2003: 23). La cobertura vegetal varía entre el 30 y el $80 \%$, apareciendo manchones de suelo desnudo (Bonino, 2005). La escasa flora se adapta a las condiciones de estrés hídrico aprovechando al máximo la poca humedad ambiente disponible; por ello, es generalmente baja, espinosa y posee hojas duras y pequeñas (follaje estacional), cutículas gruesas (follaje resinoso) o ramas verdes sin follaje, lo que le permite minimizar la perdida de agua por transpiración. Sin embargo, pueden distinguirse tres estratos: uno superior que alcanza los $200 \mathrm{~cm}$ de altura y es muy disperso, un estrato medio que ronda los 50 a $150 \mathrm{~cm}$ de altura y rara vez supera el $40 \%$ de cobertura, y un estrato inferior que ocupa un 10 a $20 \%$ con gramíneas, hierbas y arbustos bajos. La formación arbustiva más común es el jarillal, compuesto por tres tipos de jarilla (Larrea $s p$, L. divaricata y $L$. nítida) asociados a zampa o sampa (Atriplex lampa), el cual favorece a las anteriores al absorber el salitre del suelo. Otras plantas comunes son matasebo (Monte aphylla), algarrobillo o alpataco (Prosopis flexuosa), monte negro (Bougainvillea spinosa), tomillo (Acantholippia seriphioides) y molle (Schinus johnstonii). El tomillo es utilizado como condimento y como té, por sus propiedades digestivas. El alpataco tiene frutos comestibles y también es utilizado para producir un 
tipo de harina, así como una bebida alcohólica; además, los indígenas utilizaban sus espinas como leznas. La jarilla es utilizada para para hacer techos, cercos y escobas, también medicinal y tintura. El monte negro tiene cualidades como planta ornamental (Fiori y Salva, 2000: 45-50). El matasebo es utilizado por sus cualidades medicinales y como leña. La sampa es utilizada en cocina como sustituto de la sal.

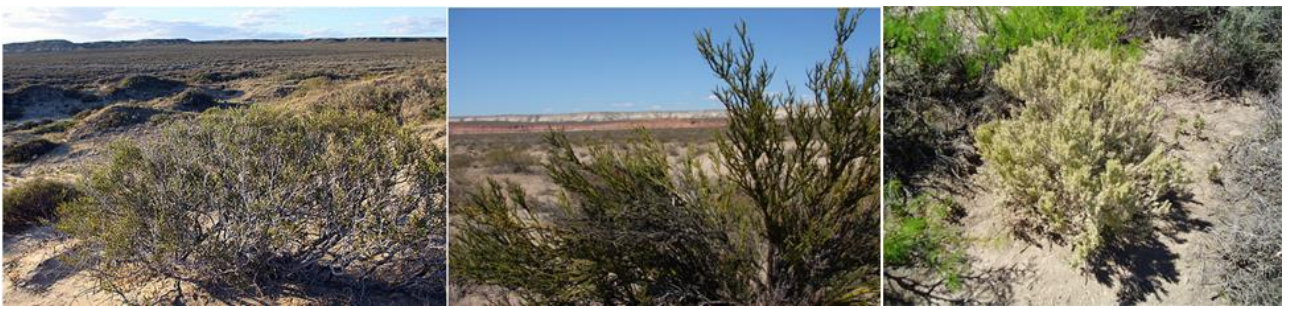

La jarilla (izquierda), el alpataco (centro) y el tomillo (derecha) son tres plantas típicas de la eco-región

En lo que respecta a la fauna, si bien en la zona occidental, más próxima a la cordillera, pueden encontrarse grandes mamíferos como pumas (Puma concolor) y guanacos (Lama guanicoe), en la meseta predominan los mamíferos cavícolas de menor porte, como el zorro gris (Pseudalopex griseus). Sin embargo, los animales con mayor representatividad son los reptiles, seguidos por aves y mamíferos, siendo los menos diversos los anfibios (Fiori y Salva, 2000: 59). Entre los anfibios, pueden encontrarse sapos (Bufo arenarum y spinulosus). Entre los reptiles, diversos tipos de lagartijas (como Liolaemus melanops, darwini, boulengeri, austromendocinus, gracilis y Cnemidophorus longicaudus) y culebras (Liophis sagittifer y Philodryas burmeisteri). Entre las aves caminadoras el choique o ñandú petiso o patagónico (Pterocnemia pennata) y entre las voladoras chimango (Milvago chimango), flamenco común (Phoenicopterus chilensis), cisne cuello negro (Cygnus melancoryphus) y tero (Vanellus chilensis). Entre los mamíferos, se encuentran el piche (Zaedyus pichi), peludo (Chaetophractus villosus), hurón mediano (Galictis cuja), gato de pajonal, gato montés (Oncifelis geoffroyi), coipo (Myocastor coypus). En cuanto a las especies en riesgo, los criterios utilizados en las diversas clasificaciones (a escala nacional y patagónica) son divergentes. Sin embargo, entre las especies vulnerables caben destacar la mara (Dolichotis patagonum), el gato de pajonal (Oncifelis colocolo) y la tortuga de tierra (Chelonoidis donosobarrosi), esta última debido al comercio ilegal de mascotas (Fiori y Salva, 2000: 59-60).
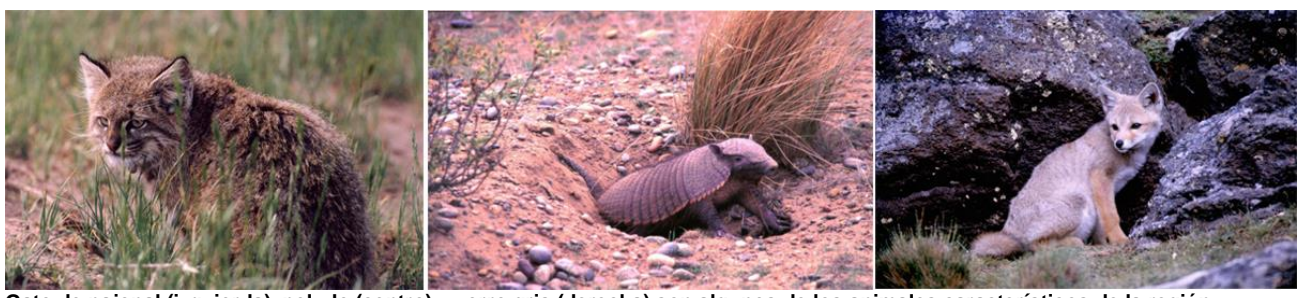

pajonal (izquierda), peludo (centro) y zorro gris (derecha) son algunos de los animales característicos de la región Fuente: Bonino, 2005

El ecosistema presenta una rica flora y fauna, que incluye especies endémicas y raras, pero a la vez es frágil y especialmente vulnerable al pastoreo. Además, la vegetación de la meseta es de lento crecimiento por lo que su recuperación también lo es. Por la pobreza de los suelos y la aridez del clima, las especies vegetales exóticas (perales, manzanos, vides, ciruelos, durazneros; álamos, cipreses y eucaliptos) no pueden reproducirse por sí solas en la meseta, sin embargo, algunos animales como la liebre europea (Lepus europaeus), el conejo europeo (Oryctolagus cuniculus) y el asno (Equus sp.) se han asilvestrado. En los ríos, las truchas marrón (Salmo trutta) y arco iris (Oncorhynchus mykiss), introducidas para la pesca deportiva, hoy incluso amenazan las especies naturales, perca (Perca fluviatilis) y pejerrey (Odontesthes bonariensis).

La construcción de sistemas de riego y control de aguas han permitido desarrollar grandes extensiones de cultivo, "poniendo en valor" las tierras de los valles fluviales primero y partes de meseta después. Los avances técnicos 
de la agricultura solucionar dificultades como la intensidad de los vientos, la salinización de los suelos, la caída de heladas tardías y granizo, utilizando tecnologías cada vez menos perjudiciales para el medio ambiente. En las áreas agrícolas se ha configurado un paisaje antrópico característico, regido por la cuadricula de $1000 \times 1000 \mathrm{~m}$ de las alamedas y caminos, así como por la presencia de canales, acequias y desagües, frutales, vid, animales de corral (ovejas, cabras, chanchos, gallinas) y caballos. Sin embargo, la sistematización de suelos y el desarrollo de grandes extensiones agrícolas "implica la simplificación de la estructura del ambiente en grandes extensiones, reemplazando la diversidad natural por un pequeño número de plantas cultivadas y animales domésticos, lo que puede llevar a una disminución de la diversidad biológica" (Ganduglia, Zanetta \& Faggi, 2017). A su vez, que el uso de agroquímicos produce diversos tipos de contaminación.

Con la mirada centrada en la meseta, Fiori y Salva (2000), detectan cuatro actividades que han afectado especialmente la conservación de las especies autóctonas, tanto animales como vegetales. Estas son:

- la extracción indiscriminada de leña hasta la sanción del Decreto provincial 1837/93, que ha afectado algunas especies vegetales;

- la ganadería extensiva por el sobrepastoreo provocado, con la consiguiente disminución de la cobertura vegetal, así como perdida de refugios y recursos alimentarios para los animales;

- la caza furtiva, bien para la venta de los animales, su consumo o "control" por parte de los crianceros. Esta ha afectado principalmente al guanaco, choique, mara, piche, peludo, peludo y puma;

- la actividad hidrocarburífera. La ejecución de picadas genera barreras que algunas especies animales como el chinchillón o pilquín (Lagidium viscacia) no pueden atravesar, quedando restringida su circulación; en estos caminos no consolidados se localizan además algunas especies vegetales exóticas muy invasivas y facilitan la circulación a cazadores y leñadores furtivos. Las piscinas de purga utilizadas por la actividad extractiva constituyen, por otra parte, trampas para las aves acuáticas, ya que actúan como ambientes acuáticos artificiales, donde los animales se posan y -en consecuencia- mueren. Por último, los eventuales derrames de petróleo o contaminación de napas freáticas también significan un riesgo para la flora y fauna.

\subsection{EI Bajo de Añelo o la Cuenca del Añelo, un desierto salado}

Se trata de una depresion cerrada de aproximadamente $280 \mathrm{~km}$ de largo, que posee los puntos mas bajos de la provincia neuquina, ya que tiene un fondo plano cuya cota media es de $225 \mathrm{msnm}$. La altura del relieve se levanta en todas direcciones, alcanzando un maximo en sus bordes exteriores de $500 \mathrm{~m}$. Constituye un rasgo estructural de escala regional, que se extiende en direccion noroeste - sudeste, desde General Roca hasta el noroeste del Volcan Auca Mahuida (Pangaro et al., 2011), en gran parte de su extensión, en forma paralela a la traza del río Neuquen. Está divido en tres segmentos (señalados en la imagen de la derecha, con las letras A, B y C), los cuales poseen diferente morfologia, mecanismos de subsidencia y evolución estructural, o que, en otras palabras, fueron modelados por diferentes procesos tectonicos, acontecidos entre el Triasico Tardio y el Mioceno (Pangaro et al., 2011). Por su gran magnitud, extensión y el momento en que se modeló, el Bajo de Añelo constituyó -en especial en los sectores oriental y central- un importante factor en el control de la migración y distribución de hidrocarburos de los distintos sistemas petroleros actuantes en su entorno, funcionado como "divisoria de aguas" del petróleo generado por la Formación Los Molles y la Formación Vaca Muerta (Pangaro et al., 2011).

Las precipitaciones ocasionan el lavado y transporte de sedimentos desde la superficie de la meseta sedimentaria, arrastrando sales minerales hacia la superficie del bajo, erosionando los suelos y generando cursos fluviales intermitentes que al estar secos poseen un color blanquecino por las sales que quedan expuestas al evaporarse el agua (ver imagen LANTEL). En términos de ocupación poblacional y prácticas agropecuarias, la gran salinidad del suelo dificulta el crecimiento de vegetacion aun más que en otras áreas de la región.

En la imagen de la izquierda puede observarse una gran concentración salina sobre la superficie de la meseta (centro izquierdo de la imagen), evidente por el color blanquecino de la misma; geoformas asociadas a procesos de erosión hídrica, es decir, cárcavas o cañadones generados por la circulación de agua (arriba y al centro de la imagen); y picadas o caminos no consolidados por el cual transitan vehiculos vinculados a la actividad hidrocarburífera (vértice inferior derecho) (Di Nicolo \& Abarca, s/f). 

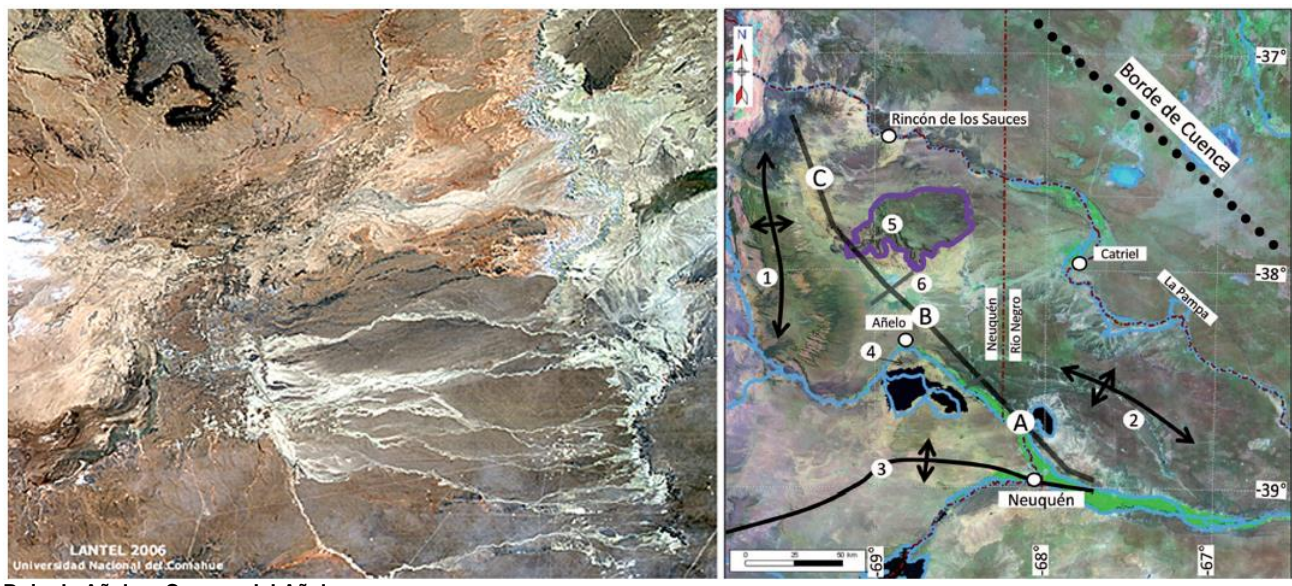

Bajo de Añelo o Cuenca del Añelo

Fuente: Atlas Neuquén desde el satélite http://atlasneuquen.uncoma.edu.ar (imagen izquierda) y Pángaro et al. (2011) (imagen derecha).

\subsection{El agua, un recurso invaluable}

En su extremo sur, el área de estudio es atravesada de oeste a este por el rio Neuquén. La cuenca del río Neuquén abarca una superficie de $32.450 \mathrm{~km} 2$ que se extiende $541 \mathrm{~km}$ desde la Cordillera de los Andes hasta su encuentro la confluencia con el río Limay, donde nace el Rio Negro.

El rio Neuquén tiene un caudal de aproximadamente $280 \mathrm{~m} 3 / \mathrm{seg}$, cuya mayor parte proviene de una importante red de cursos localizados en la zona andina. En consecuencia, posee un régimen torrencial pluvio-nival, es decir, con una crecida en otoño - invierno producida por las precipitaciones en la cordillera y otra, más importante, debido al deshielo en primavera - verano (Dalman \& Michaux, 1989), presentando valores extremos de 32 a 600 $\mathrm{m} 3 / \mathrm{seg}$ (FUNDASUR, 1998). Por la morfología de su cuenca, "el ancho de su lecho es de $80 \mathrm{~m}$ en Paso de los Indios, de unos $600 \mathrm{~m}$ en aguas medias hasta llegar a $1200 \mathrm{~m}$ en aguas altas" (Ferrera \& Michalijos, 2004). 

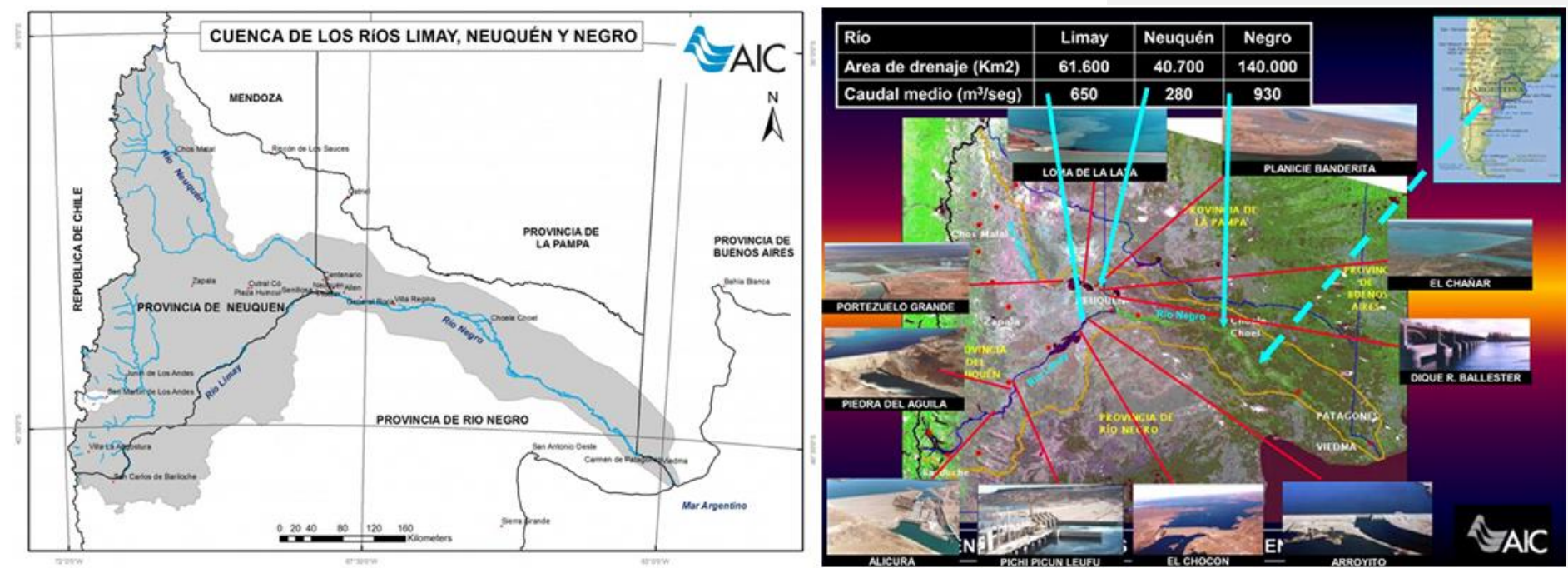

Cuenca de los ríos Limay, Neuquén y Negro

Fuente: Autoridad Intersjurisdiccional de Cuencas

La cuenca del rio Neuquén se corresponde con el sector que Capua (2003) denomina "Depósitos aterrazados vinculados al curso inferior del rio Neuquén", debido a que a lo largo del curso del rio Neuquén se identifican varios niveles escalonados que constituyen amplias terrazas de diverso tipo con un grado de cementación decreciente hacia los niveles inferiores. Dichas terrazas fluviales conforman el piso del valle actual, una planicie de inundación cuyo suelo está compuesto de relleno aluvial de gran fertilidad. En este sector, la altitud ronda los 400 a 600 msnm, el valle comienza a hacerse más amplio, la pendiente y el cauce se reducen, el rio se desplaza hacia el sur, posee un mayor número de meandros, las terrazas de inundación son más amplias y configuran las zonas de mayor potencial agrícola y forestal de la provincia (Dalman \& Michaux, 1989). Según la clasificación de suelos por su aptitud de uso (USDA), el $30 \%$ de los suelos de esta microrregión son de clase 2 o 3, es decir, aptos para la agricultura intensiva bajo riego, mientras que el otro $70 \%$ son adecuados para la ganadería (AAVV, 1999). A su vez, en los perilagos, las napas freáticas artificiales mantienen humedecidos los suelos, por lo que es posible aprovecharlos tanto para fines productivos como recreacionales (AAVV, 1999).

Por el mayor desarrollo del piso del valle en la margen Norte y el tipo de suelos a uno y otro lado del curso de agua, las áreas cultivables se localizan principalmente sobre dicha margen. Sauzal Bonito constituye el primer valle de la cuenca inferior del rio Neuquén, con un total de 3.689 hectáreas. Añelo (desde Portezuelo Grande a oeste hasta Punta Sierra al este) cuenta con 15.310 hectáreas, de las cuales entre el $35 \%$ y el $70 \%$ son de tipo 6 , es decir, aptas para la ganadería pero no para la agricultura. El Chañar cuenta con 10.000 hectáreas, sistematizadas en tres etapas y localizadas tanto en el valle como sobre la meseta. Además también es posible poner en producción tierras altas de planicie como Cerros Colorados al este y sureste del lago Mari Menuco, la planicie Banderita el Cerro Colorado, el Cordón del Cerro Colorado y la Loma de la Lata. 

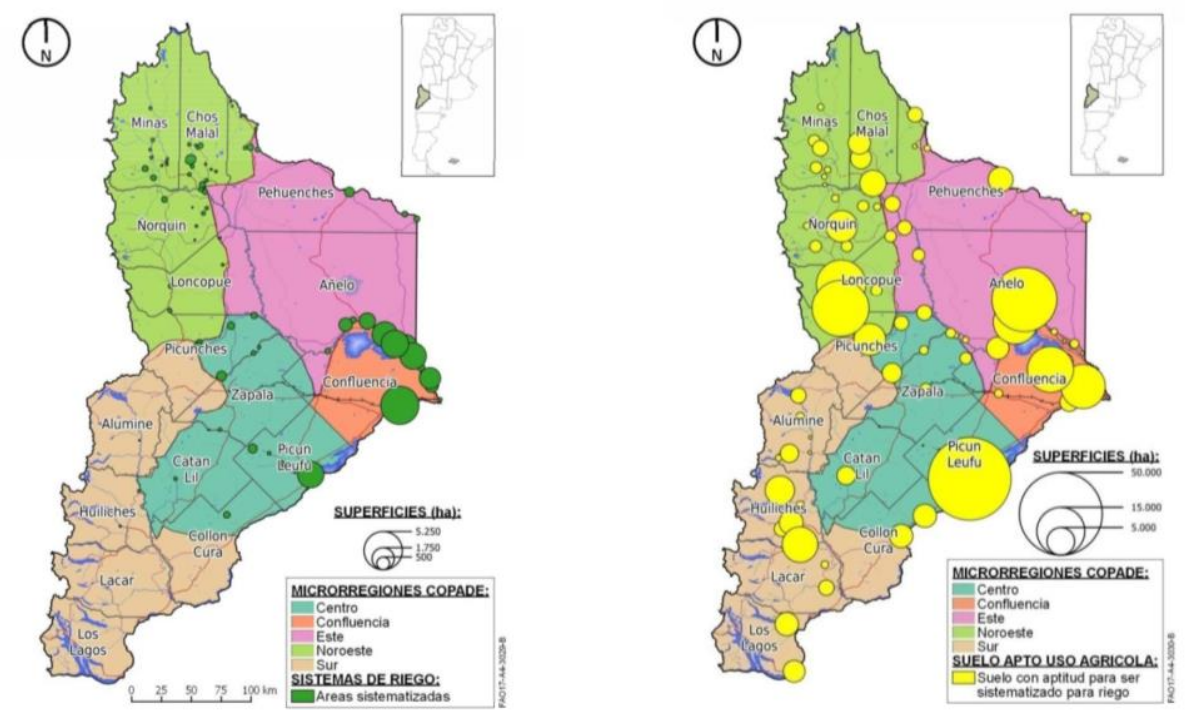

Áreas bajo riego, actuales y potenciales al 2015

Fuente: Diagnostico y prospectiva del potencial de ampliación de áreas bajo riego en la Provincia del Neuquén, FAO, 2015.

Si bien se trata de uno de los sectores más áridos de toda la provincia, con precipitaciones que no superan los $130 \mathrm{~mm}$ anuales (FUNDASUR, 1998; Perilli, 2006) y no más de 40 días al año con precipitaciones mayores a 1 $\mathrm{mm}$, la potencialidad del área para la agricultura se ve potenciada por el hecho de que constituye, además, la zona más cálida y con el periodo libre de heladas más largo de toda la provincia (150 a 180 días por año) (Perilli, 2006). Por otra parte, existen conflictos de tipos diversos entre las actividades agrícolas y extractivas que tornan poco plausible la sistematización de tierras donde se realiza o prevé la extracción de hidrocarburos, como ser: riesgo de contaminación por filtraciones de petróleo; atracción de insectos perjudiciales a la fruta por la iluminación utilizada por la actividad hidrocarburífera y por el polvo que tránsito de vehículos levanta; y, competencia por la mano de obra, debido a los elevados salarios de la actividad extractiva, con los cuales la frutihortícola no puede competir.

En cuanto a los asentamientos humanos, las limitantes al crecimiento de las localidades ubicadas en el Valle están principalmente asociadas a los riesgos naturales de inundación y desprendimientos de suelos. En el caso de la localidad de Añelo, es necesario dejar, respecto de la cabecera de la barda, 20 metros libres de cimentaciones y $5 \mathrm{~m}$ libres de todo uso a fin de minimizar la inestabilidad de la misma. Además, al piedemonte se recomienda dejar como mínimo una distancia libre de $30 \mathrm{~m}$ o de la mitad de la altura de la barda, la que sea mayor $\operatorname{AAVV}(s / f)$. 


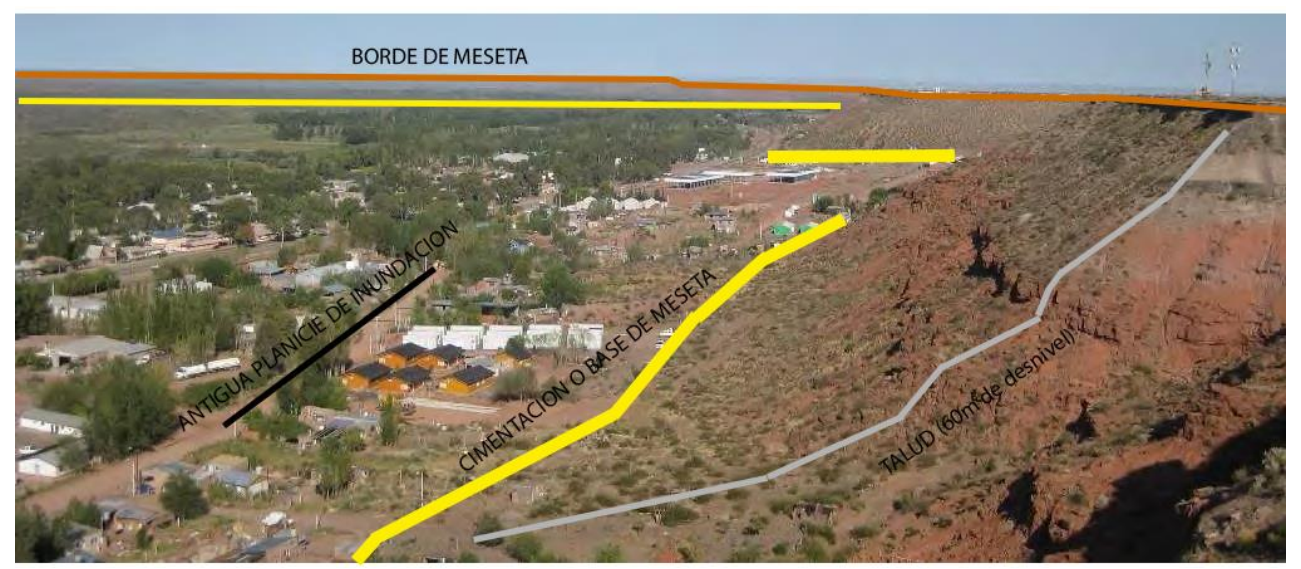

Barda de Añelo

Elaboración propia en base a Consultoría para la elaboración de proyectos ejecutivos para el mejoramiento urbano integral del centro de Añelo, Neuquén. Informe final, parte I.

\section{UNA PROVINCIA PETROLERA}

Si bien la presencia de hidrocarburos en la Provincia del Neuquén es conocida desde el siglo XIX, seria en 1912 cuando el Dr. Anselmo Windhausen daría a conocer ante los miembros de la Sociedad Científica Argentina los resultados de los primeros estudios geológicos sobre la existencia de petróleo en la Cuenca Neuquina. Esta abarca la mayor parte de la provincia del Neuquén, el suroeste de Mendoza, y el sector occidental de la Pampa y de Rio Negro, ocupando una superficie total de $124.000 \mathrm{~km}^{2}$. Gracias a ella, la extracción de hidrocarburos sería, desde 1918, una de las principales actividades económicas de la provincia.

Las primeras explotaciones se realizaron en el área entre Plaza Huincul y la ciudad de Neuquén, induciendo la fundación de las localidades de Cutral Co en 1933 y Plaza Huincul en 1966, las cuales al día de la fecha cuentan con cerca de 50.000 habitantes. Hacia la década de los sesenta la declinación de las reservas en esta zona condujo a la necesidad de explorar y explotar nuevas áreas de la provincia, lo que conduciría al descubrimiento de crudo en Puesto Hernández en 1968, un campo en las inmediaciones de la actual ciudad de Rincón de los Sauces, que sería fundada cuatro años más tarde, y de Chihuido de la Sierra Negra Lomitas en 1988. Estos yacimientos impulsaron el crecimiento de Rincón, que en el presente cuenta- con aproximadamente 20.000 habitantes.

Por otra parte, el descubrimiento del yacimiento gasífero Loma La Lata en 1977 (complementado con Aguada Pichana a partir de 1980), Aguada San Roque, 1986, Loma de las Yeguas, 1986 y Sierra Chata, 1993) provocó un en la matriz energética del país y el desarrollo de una gran red de gasoductos troncales. Sin embargo, no se tradujo en un desarrollo urbano como los nombrados en el párrafo anterior, sino que se nutrió principalmente de trabajadores provenientes de las áreas urbanas consolidadas. En consecuencia, si bien la población de Añelo creció significativamente en términos porcentuales, hacia el 2010 contaba tan sólo con unos 2.600 habitantes.

En los primeros años del siglo XXI una tercera declinación de las reservas en la provincia conduce a volcar a Repsol - YPF las miradas en la Formación Vaca Muerta, uno de los estratos de la Cuenca Neuquina, la cual había sido descripta por el geólogo Charles E. Weaver unos noventa años atrás, pero de la cual no había sido posible cuantificar sus reservas, ubicadas entre 1.200 y $2.500 \mathrm{~m}$ de profundidad. Por otra parte, hasta la década de los noventa no había sido económicamente viable extraer hidrocarburos no convencionales como los de este estrato, debido a lo oneroso del proceso y lo recientes de las investigaciones sobre el mismo. Se trata de un método que permite extraer gas y petróleo de la roca generadora (shale) o desde mantos de arenas compactas (tars sands) donde quedan retenidos en su migración (tight), mediante un método de fractura hidráulica conocido como fracking. 


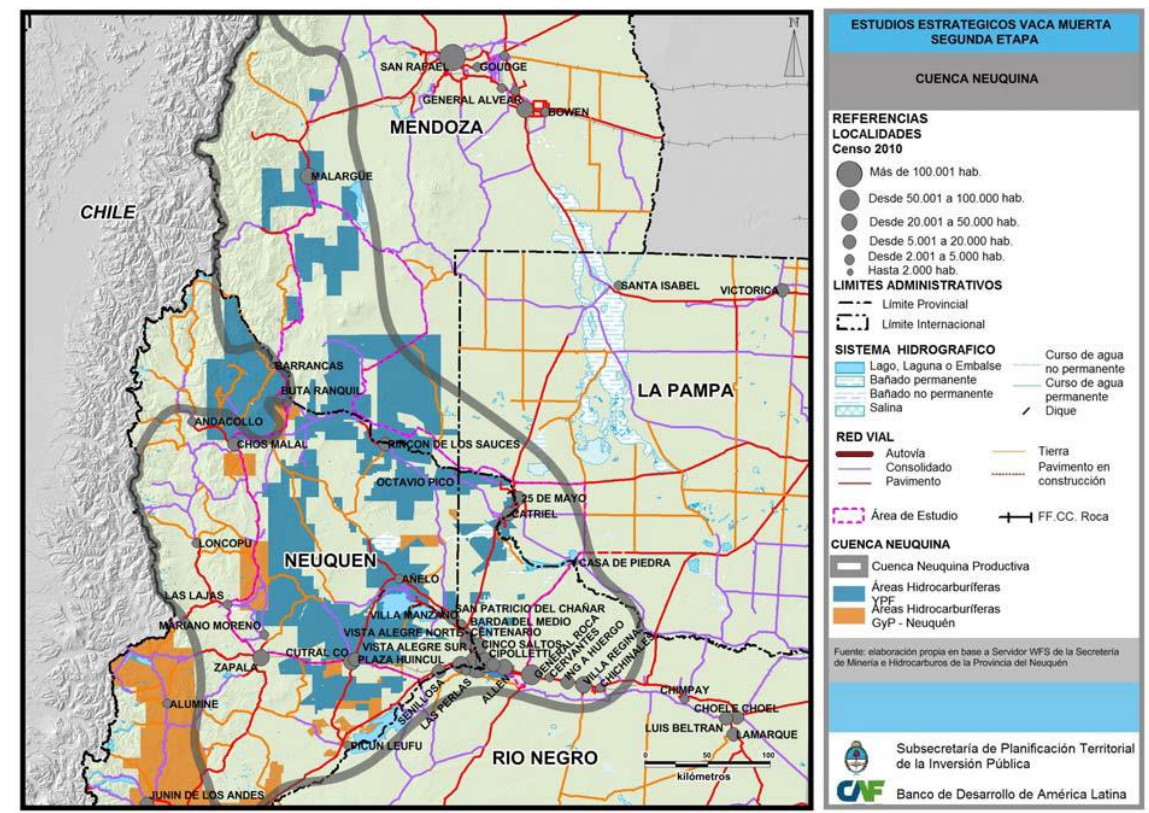

Áreas hidrocarburíferas de la Cuenca Neuquina.

Fuente: Estudios Estratégicos Vaca Muerta. Segunda Etapa.

La Formación Vaca Muerta, tiene una superficie de $56.000 \mathrm{~km}^{2}$, un espesor de 60 a $520 \mathrm{~m}$ y un área extractiva dividida en la dirección este - oeste en tres franjas, una con concentración de petróleo (que representa el 77 \% de los volúmenes presentes en el estrato), una con gas y otra con thight gas. Esta segmentación geográfica por tipo de hidrocarburo puede determinar diferentes dinámicas de explotación, asociadas a los precios de cada tipo de hidrocarburo, a la vez que la diversidad de espesores permite en algunos sectores realizar perforaciones verticales, menos costosas y, por tanto, más rentables (AAVV, 2016). 


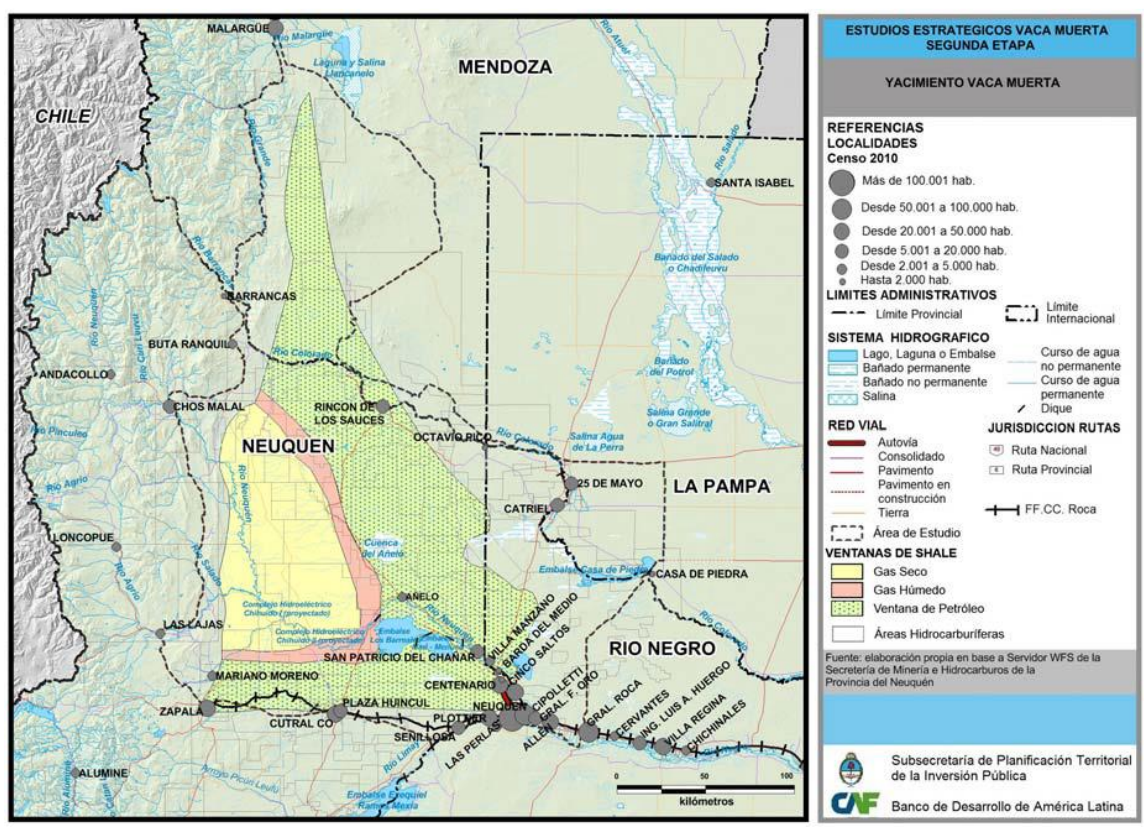

Yacimiento Vaca Muerta y principales aglomeraciones urbanas

Fuente: Estudios Estratégicos Vaca Muerta. Segunda Etapa

En 2010, Repsol - YPF comienza las operaciones para poner en funcionamiento un primer pozo de Shale Gas en Loma La Lata; a finales del 2011 anuncia públicamente la existencia de reservas probadas en torno a los 927 millones de barriles equivalentes de petróleo (BEP) en la Formación, número que ascendería a 22.500 millones para febrero del 2012. La posibilidad de explotar estas enormes reservas elevó las expectativas de múltiples actores, debido a los beneficios económicos para las empresas implicadas en su explotación, la capacidad de las reservas de garantizar a Argentina su autosuficiencia energética, los procesos migracionales que este tipo de explotaciones inducen y el dinamismo económico que se genera en torno a los mismos. Dichos actores incluyen a los diversos niveles gubernamentales, lo cual se tornó evidente ante la expropiación de las acciones del grupo español Repsol sobre la empresa energética en mayo 2012, y, en 2013, a un acuerdo entre la renacionalizada YPF y Repsol para financiar y ejecutar el "Plan Piloto", que implica una inversión de U\$S 1.500 millones para poner en funcionamiento más de 100 pozos, distribuidos en un área de $20 \mathrm{~km}^{2}$ localizada en Loma La Lata Norte y Loma Campana. Sin embargo, la caída del precio internacional del petróleo en 2014, fecha desde la cual se mantiene por debajo del umbral de rentabilidad, ha causado la ralentización de las inversiones previstas; sin embargo, la centralidad geográfica de la localidad de Añelo respecto de las primeras explotaciones repercutió en la misma con aumento demográfico, en los precios del suelo y los alquileres, e inversiones públicas y privadas. 


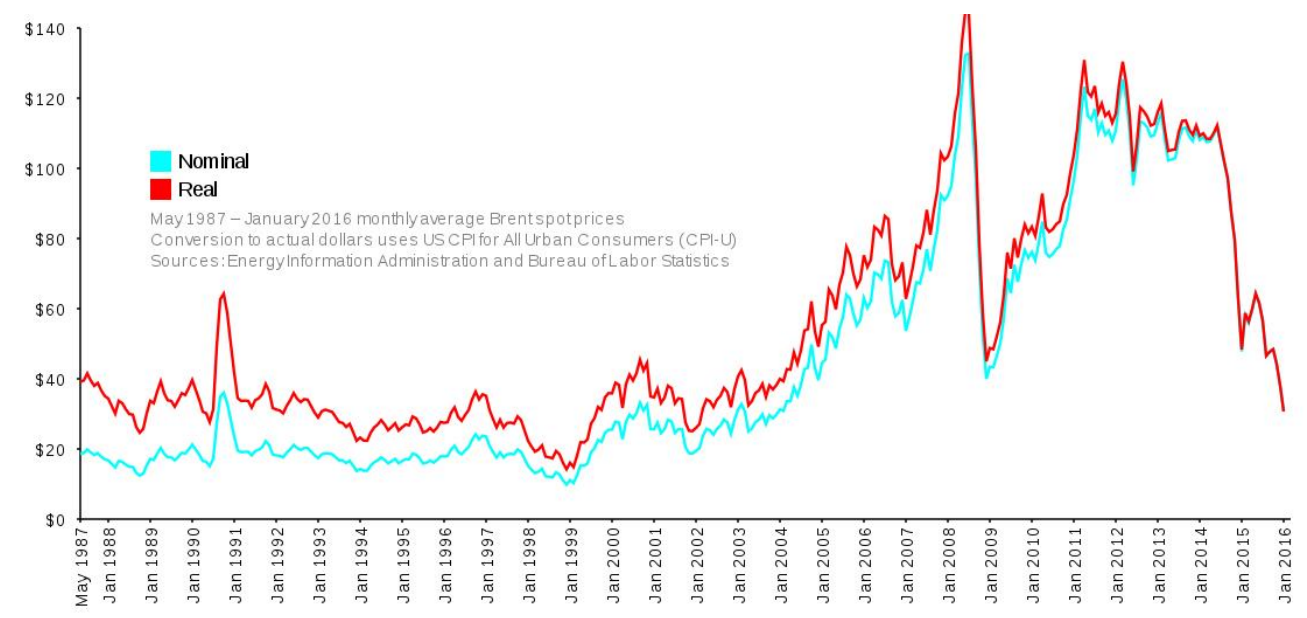

Gráfico de la evolución de los precios del petróleo a largo plazo (1987-2016), nominales y reales, indicados en dólares

Fuente: Administración de Información Energética (EIA) de Estados Unidos.

\section{PATRIMONIO NATURAL Y PAISAJÍSTICO}

En su mayor parte, se trata de un área que durante el Paleoceno se encontraba abarcada por el mar. En consecuencia, existen yacimientos paleontológicos en diversos sitios, así como formaciones geológicas propias a los procesos de transgresión marina.

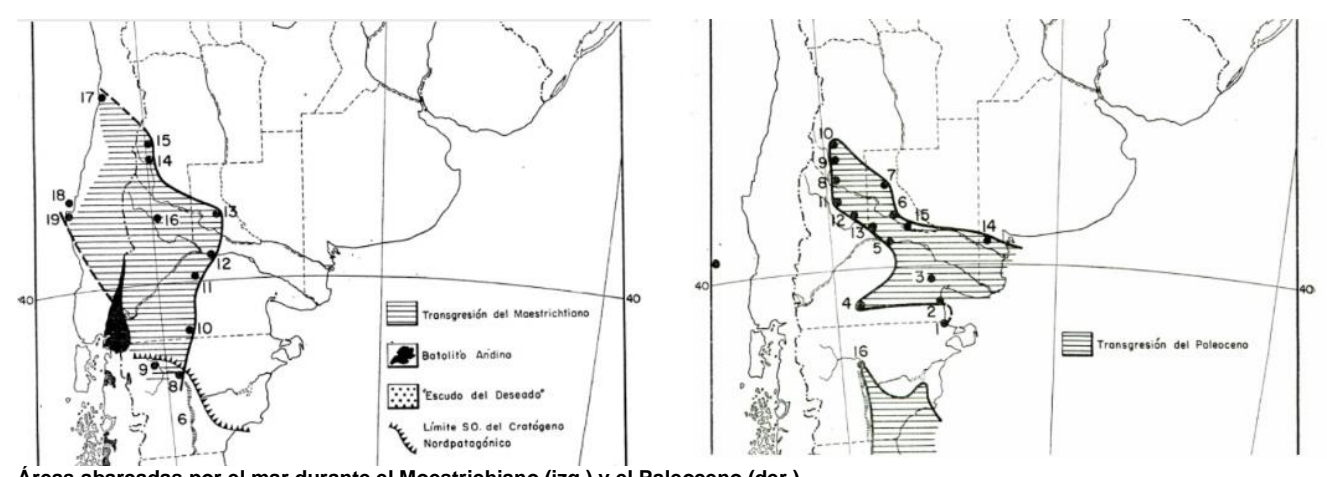

Áreas abarcadas por el mar durante el Moestrichiano (izq.) y el Paleoceno (der.).

Elaboración propia en base a Camacho, 1967.

Otro conjunto de formaciones de la Cuenca Neuquina son el Grupo Neuquén, antes conocidas como "Estratos con Dinosaurios". El Grupo Neuquén reúne una sucesión de depósitos continentales, conocidos como "capas rojas" por su color, con un espesor de hasta 1.200 metros. Estos depósitos se desarrollaron durante gran parte del Cretácico Superior (100 a 70 millones de años atrás) y conforman los afloramientos mesozoicos de mayor distribución areal dentro de la Cuenca Neuquina. Resultan de gran valor científico, patrimonial y turístico, ya que en ellos es posible encontrar fósiles de vertebrados que incluyen dinosaurios. Por otra parte, al encontrarse las Formaciones que componen este Grupo por encima de los depósitos hidrocarburíferos, pueden existir conflictos con la actividad hidrocarburífera. 
Como puede observarse en el mapa a continuación, existen importantes afloramientos del Grupo Neuquén tanto en la Provincia homónima como en Rio Negro, siendo de particular interés para nosotros los localizados en la Cuenca del rio Neuquén y en la Cuenca de Añelo, así como al este y norte de nuestra región de estudio.
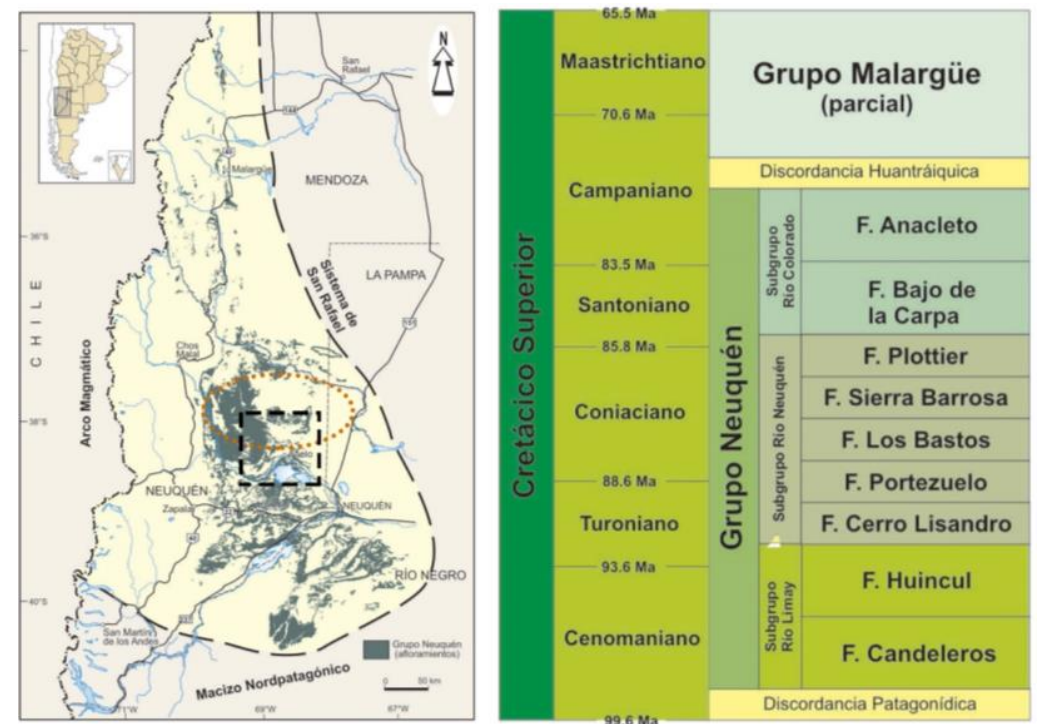

IZQUIERDA: Mapa de distribución de los afloramientos del Grupo Neuquén, Cretácico Superior continental de la Cuenca Neuquina, en relación a nuestra área de estudio y al área de influencia de las actividades hidrocarburíferas no convencionales Elaboración propia en base a Garrido, 2011.

DERECHA: Esquema litoestratigráfico del Grupo Neuquén

Fuente: Garrido, 2011.

Así mismo, la geomorfología genera paisajes exóticos de gran atractivo turístico, como ser las columnas de erosión eólica en depósitos de la Formación Bajo de la Carpa, Los Mogotes (Tratayén), conocidos popularmente como "monigotes" o "pilares". Estos pueden observarse aproximadamente a $10 \mathrm{~km}$ al este de la localidad de Añelo, sobre la vera de la Ruta Nacional $N^{\circ} 7$, en un campo privado. Los monigotes son extremadamente llamativos en tanto rondan los 20 a $30 \mathrm{~m}$ de alto y detrás de los ellos se encuentran "paredes" de barda donde loros barranqueros (Cyanoliseus patagonus) escarban sus nidos, a las cuales se las conoce como "tratayanes".
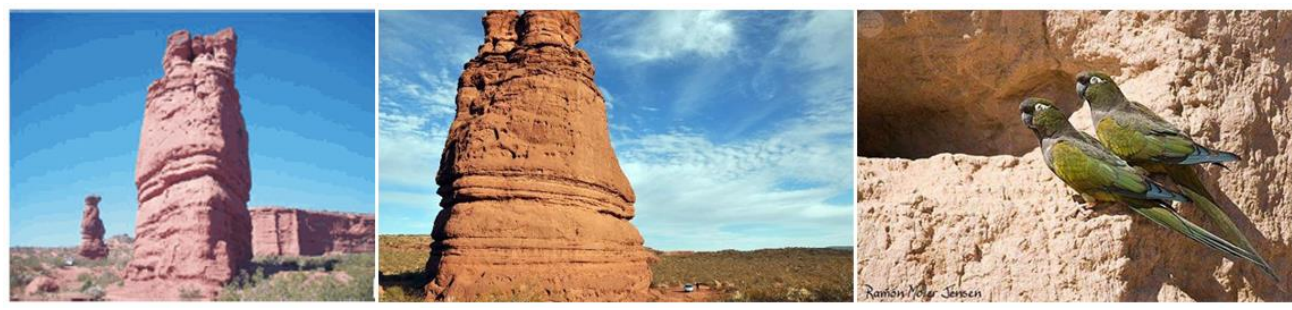

Monigotes y loros barranqueros: algunos de los atractivos turísticos de Añelo

\section{CONCLUSIONES}


Los cambios inducidos por la explotación de hidrocarburos no convencionales en el territorio y sus actores nos indujeron a preguntarnos sobre el proceso de construcción del paisaje de Añelo. La Formación Vaca Muerta significó para nosotros nuestra primera escala de aproximación, en tanto se traduce en la potencial área de explotación, dentro de ella, las áreas donde se está realizando la "prueba piloto" y que se definieron como de "incidencia" constituyeron un segundo plano de análisis. En forma paralela, las dinámicas sociales históricas de las ciudades petroleras de la Norpatagonia nos condujeron a decidir construir un área en la cual Añelo sea la única "ciudad petrolera", con esta premisa, tomamos la decisión de restringirnos a la Provincia del Neuquén. Por otra parte, la disponibilidad de datos censales históricos y las características de los índices sociodemográficos departamentales nos indujo a considerar únicamente los datos del Departamento Añelo. Luego, las áreas geomorfológicas y fisiográficas nos obligaron a realizar un zoom out, para después permitirnos establecer límites más precisos, una región más acotada a la localidad que nos interesa: Añelo.

Probablemente, el estudio más profundo de las dinámicas sociales y las transformaciones al medio físico desarrolladas a lo largo de los siglos nos obligue a redefinir los límites de nuestra área de estudio. Asimismo, nos veremos en la obligación de realizar nuevos zoom in y zoom out, en función de la extensión geográfica con que cada proceso, hecho y/o estrategia se vincule. Sin embargo, el trabajo hasta aquí realizado nos permite contar con un área de análisis adecuada para comenzar a realizar dichos estudios.

\section{BIBLIOGRAFÍA}

AAVV (s/f). Consultoría para la elaboración de proyectos ejecutivos para el mejoramiento urbano integral del centro de Añelo, Neuquén. Informe Final. Parte I. YPF - IDOM. Recuperado de https://www.argentina.gob.ar/interior (Consulta: 3/03/2018).

AAVV (1999). Programa jóvenes Entrepeneurs. Microrregión Añelo. Propuesta socio - educativa - productiva ambiental viable para el desarrollo autosustentable. Disponible en http://www.copade.gob.ar (Consulta: 3/03/2018).

AAVV (2016). Estudios estratégicos para el desarrollo territorial de la Región Vaca Muerta. Segunda Etapa. Vol. 1, COFEPLAN. Disponible en https://www.mininterior.gov.ar (Consulta: 3/03/2018).

BANDIERI, S. (2014). Acerca del concepto de región y la historia regional: la especificidad de la Norpatagonia. Revista de Historia, (5), 277-293. Recuperado de http://www.unisinos.br/publicacoes_cientificas/images/stories/Publicacoes/historiav13n1/19a34_art02_carb onari.pdf

BONINO, N. (2005). Guía de mamíferos de la Patagonia Argentina. Instituto Nacional de Tecnología Agropecuaria (Argentina).

CAMACHO, H. H. (1967). Las transgresiones del Cretácico superior y Terciario de la Argentina. Revista de la Asociación Geológica Argentina, 22(4), 253-280.

CAPUA, O. (2014). Fisiografía y paisajes del Neuquén. Boletín Geográfico, (23), 9-29.

CARBONARI, M. R. (2009). De cómo explicar la región sin perderse en el intento. Repasando y repensando la Historia Regional. História Unisinos, 13(1), 19-34. https://doi.org/10.4013/htu.2009.131.02

DALMAN, A., \& MICHAUX, A. (1989). Proceso de ocupación del valle de Añelo. Universidad Nacional del Comahue, Neuquén, 80 pp.

DE JONG, G. M. (2001). Introducción al método regional. Laboratorio Patagónico de Investigación para el Ordenamiento Ambiental y Territorial, Facultad de Humanidades, Universidad Nacional del Comahue.

DÍAZ TERRENO, F. (2013). Constelaciones rurales serranas. Lógicas de ocupación del territorio y modelos de orden. Lecturas interpretativas de la construcción histórica del Norte de Traslasierra, Córdoba, Argentina. Revista 
Digital Labor \& Engenho, 7(3), $37 \quad$ - $58 . \quad$ Recuperado de https://periodicos.sbu.unicamp.br/ojs/index.php/labore/issue/view/171 (Consulta: 1/05/2018).

FERRERA, I. M. \& MICHALIJOS, M. P. (2004). Los recursos hídricos en el sistema norpatagónico: perspectivas para el tercer milenio. Encuentro Humbolt.

FIORI, S.M. y S.M. ZALBA (Eds.) 2000. Plan de Manejo Reserva Provincial Auca Mahuida (Neuquén). Volumen I - Diagnóstico Regional. Secretaría de Estado del COPADE y Consejo Federal de Inversiones. 205 pp.

FUNDASUR (1998). Estudio de la microrregión de Añelo. Disponible en http://www.copade.gob.ar (Consulta: 3/03/2018).

GANDUGLIA, O., ZANETTA, E., \& FAGGI, A. (2017). El Rol de las Plantas Exóticas en la Homogeneización y Diferenciación Florística en Argentina. Terra Mundus, 3(2).

GARRIDO, A. C. (2011). El Grupo Neuquén (Cretácico Tardío) en la Cuenca Neuquina. En Relatorio del 18 Congreso Geológico Argentino (Vol. 1, pp. 231-244).

GONZÁLEZ DÍAZ, E. F. y DI TOMMASO, I. (2011). Geomorfología. En Relatorio del 18 Congreso Geológico Argentino (pp. $421-438$ ).

PÁNGARO, F. et al. (2011). El Bajo de Añelo. En Relatorio del 18 Congreso Geológico Argentino (Vol. 1, pp. 399 $-405)$.

PASTOR, G. C. (2008). La construcción del paisaje cultural en la ordenación del espacio turístico: el Valle de Tafí. (Disertación Doctoral, Universidad de Sevilla).

PERILLI (2006). Plan de ordenamiento territorial y ambiental en las localidades de Añelo, San Patricio del Chañar y Sauzal Bonito. Primer informe parcial. Disponible en http://www.copade.gob.ar (Consulta: 3/03/2018).

PERREN, J. (2009). “Una transición demográfica en el fin del mundo". La población de la provincia de Neuquén (Patagonia, Argentina) durante el siglo XX tardío. Scripta Nova: revista electrónica de geografía y ciencias sociales, 13.

RAMOS, V. A., FOLGUERA, A., \& GARCÍA MORABITO, E. (2011). Las provincias geológicas del Neuquén. En Geología y Recursos Naturales de la Provincia del Neuquén. Relatorio 18ํㅡㄴ Congreso Geológico Argentino, Neuquén (pp. 317-326).

SAUER, C. O. (2006) [1925]. La morfología del paisaje. Polis. Revista Latinoamericana, (15).

OJEDA, R. A., CHILLO, V., \& ISENRATH, G. D. (2000). Libro rojo de mamíferos amenazados de la Argentina. Sociedad Argentina para el Estudio de los Mamíferos.

\section{Fuentes electrónicas:}

http://www.aic.gob.ar (Consulta: 3/03/2018).

http://www.anp.gov.ar/auca mahuida.html (Consulta: 3/03/2018).

http://atlasneuquen.uncoma.edu.ar (Consulta: 3/03/2018).

http://www.copade.gob.ar (Consulta: 3/03/2018).

https://inta.gob.ar (Consulta: 3/03/2018).

http://www.patrimonionatural.com (Consulta: 3/03/2018).

Comentado [m1]: http://www.copade.gob.ar/contenido .aspx? Id=NOV-8462

https://inta.gob.ar/documentos/mapa-geoespacial-

neuquen

http://www.patrimonionatural.com/HTML/provincias/neu

quen/delmonte/flora.asp 
